\title{
Printability, microstructure, and flow dynamics of phase-separated edible 3D inks
}

\author{
Sara M. Oliveira ${ }^{\mathrm{a}}$, Luiz H. Fasolin ${ }^{\mathrm{b}}$, António A. Vicente ${ }^{\mathrm{b}}$, Pablo Fuciños ${ }^{\mathrm{a}}$, Lorenzo \\ M. Pastrana ${ }^{\text {a,* }}$ \\ ${ }^{a}$ International Iberian Nanotechnology Laboratory, Department of Life Sciences. Av. Mestre José Veiga s/n, 4715-330, Braga, Portugal \\ ${ }^{\mathrm{b}}$ CEB - Centre of Biological Engineering, Universidade do Minho. Campus de Gualtar 9, 4710-057 Braga, Portugal
}

\section{A R T I C L E I N F O}

\section{Keywords:}

Food-ink

Whey proteins

Printability

3D printing

Phase separation

Flow dynamics

\begin{abstract}
A B S T R A C T
Personalizing the nutrition and sensorial attributes of 3D printed foods primarily requires various multiscale properties to be individually tailored. Herein, multiscale inks are produced by segregative phase separation, a candidate for further 3D inks texture control, of gellan gum (GG), and whey protein isolate (WPI). The inks microstructure, rheological properties, flow dynamics, their impact on printability, and properties-variables interactions are analyzed using experimental design and clustering. The gels are a GG matrix structured with WPI beads or fibers ranging from $<5$ to $>100 \mu \mathrm{m}$ in diameter. A straightforward, six-step printability test determines that high-quality prints require increasing viscosity, which is obtained by reducing the size and length of the WPI beads. Also, flow dynamics and rheology models predict the shear stress and extrusion force, according to the print settings and food-inks fluid properties. The phase-separated inks enable printing at high speed $(>25 / 50 \mathrm{~mm} / \mathrm{s})$ upon low extrusion forces $(<50 \mathrm{~N})$ and low shear stresses $(<500 \mathrm{~Pa})$, according to the calculations and model validation.

These printability evaluation methodologies and fabrication of phase-separated inks are particularly interesting for 3D food printing, bioprinting, or biomaterials applications.
\end{abstract}

\section{Introduction}

Micro-extrusion-based 3D food printing is an additive manufacturing technique that entails the layer-by-layer fabrication of foods with a controlled 3D structure (Z. Liu, Zhang, Bhandari, \& Wang, 2017). This technology enables new business opportunities and new innovative products for food personalization (Pallottino et al., 2016). While some foods are intrinsically printable (e.g., butter, mashed potatoes), many others are not homogeneously extrudable and do not sustain the weight of the subsequent layers (Godoi, Prakash, \& Bhandari, 2016). Therefore, many studies have sought to improve the printability of foods and to understand the impact of rheological properties and post-processing. Various printable foods have been reported, including chocolate (Lanaro et al., 2017), surimi gel (Yang, Zhang, Bhandari, \& Liu, 2018), lemon juice (Yang et al., 2018), cheese (Le Tohic et al., 2018), mashed potato (Z. Liu, Zhang, Bhandari, \& Yang, 2018), milk protein (Y. Liu et al., 2018, 2019), pectin (Vancauwenberghe et al., 2017; Vancauwenberghe, Verboven, Lammertyn, \& Nicolaï, 2018), cookie dough
(Kim et al., 2019), processed meat (Dick, Bhandari, \& Prakash, 2019), bio-inks for plant cells (Vancauwenberghe, Delele, et al., 2018), functional cookies (Vieira et al., 2020), and vegetable powders (Kim et al., 2018). The texture of the resulting 3D printed foods is of concern, and the ability to tune the final texture without compromising printability remains a challenge. Researchers continue to augment texture by changing the composition (e.g., hydrocolloid type or concentration), the internal infill 3D structure (pattern or percentage), the number of perimeters/shells, and/or porosity (Kim, Bae, \& Park, 2017; Z.; Liu, Bhandari, Prakash, \& Zhang, 2018; Mantihal, Prakash, \& Bhandari, 2019; Vancauwenberghe, Delele, et al., 2018). However, controlling the texture of 3D printed foods at the filament scale is far more challenging. The processing methodologies that affect texture-related characteristics may also alter printability. Therefore, food-inks displaying versatile gelation, a structuring mechanism (i.e., prior, in situ, or post-printing), and intrinsic properties are still needed.

Proteins, fats, and polysaccharides are the main ingredients used to control the texture and structure of food products. Proteins and

\footnotetext{
* Corresponding author.

E-mail address: lorenzo.pastrana@inl.int (L.M. Pastrana).
} 
polysaccharide structuration via phase separation (segregative or aggregative) might be of use for 3D food-printing applications (Le, Rioux, \& Turgeon, 2017; Turgeon, Beaulieu, Schmitt, \& Sanchez, 2003; van de Velde, de Hoog, Oosterveld, \& Tromp, 2015; Wijaya, Patel, Setiowati, \& Van der Meeren, 2017). This process generates microstructures and gels with tunable mechanical properties; however, very little is known regarding the printability of such food-inks. The primary goal of the current research was to explore phase separation for 3D food-printing applications. We used whey protein isolate (WPI) and gellan gum (GG) in the selected system. This process is especially interesting due to its high versatility with regard to gelation and structuring mechanisms (Esquena, 2016; Wakhet et al., 2015).

The gelation of whey proteins can be accomplished through several processes, including ionic crosslinking, acidification, heating, high pressure, high/moderate voltage, and enzymatic treatment (Havea, Singh, \& Creamer, 2001; Ju \& Kilara, 1998; Truong, Clare, Catignani, \& Swaisgood, 2004). The hydrophobic/hydrophilic balance and gelation properties of whey proteins have been useful for texture (Boye, Alli, Ismail, Gibbs, \& Konishi, 1995; van de Velde et al., 2015), composition modification (Barbut \& Foegeding, 1993), emulsification (Yamauchi, Shimizu, \& Kamiya, 1980), encapsulation, and nano- and micro-structuring of foods (Boye et al., 1995; Havea et al., 2001; van de Velde et al., 2015). In addition to providing essential amino acids, other health and nutritional benefits have been demonstrated, such as antioxidant activity, insulin regulation, anti-obesity, osteo-protection, anti-inflammatory properties, antimicrobial properties, growth factor activity, and muscle gain (Khan, Amin, Ansari, \& Majumder, 2015; McIntosh et al., 1998; Patel, 2015; Smithers, 2008).

Gellan gum, which is an anionic exopolysaccharide obtained by bacterial fermentation (e.g., Sphingomonas elodea) (Prajapati, Jani, Zala, \& Khutliwala, 2013; Tang, Tung, \& Zeng, 1997), is a highly versatile compound. GG has a low charge density $(<0.3 \mathrm{~mol} / \mathrm{mol}$ monosaccharide) (de Jong, Klok, \& van de Velde, 2009), and its gelation can be induced even at low concentrations with mono- or divalent cations or by heat-cold treatment. Depending on the deacetylation degree of the GG, its gelation behavior might also be thermo-reversible (Bajaj, Survase, Saudagar, \& Singhal, 2007; Kang \& Veeder, 1983; Prajapati et al., 2013).

Phase separation is a promising processing technique that we chose to exploit for this work, because of its intrinsic properties and the possible effect on printability. The impact of the biopolymers on the ink structure and its fluid properties was assessed by rheometry and confocal microscopy. In addition, full factorial design with five factors was employed to quantify the effect of the print settings and the biopolymer concentrations on the fidelity of the resulting 3D shapes. Moreover, the linear correlations between the printability and the main attributes of the printed inks were evaluated by heat-map clustering. Also, by using flow dynamics and rheology models, the shear stress and the extrusion force were estimated in accordance with the printing settings as an additional tool for the prediction of printability.

The present study aims to present a set of tools and procedures that allow for an objective evaluation and prediction of the printability of edible biopolymer blends. The tools are applied to phase-separated inks to understand what intrinsic properties are required to improve the printability of WPI.

\section{Materials and methods}

\subsection{Materials}

Whey protein isolate 97\% (WPI, Bulk Powders - $<0.5 \%$ fat) and high acyl gellan gum (GG - Gellan, Albert y Ferran Adriá) were obtained and used as-received in the preparation of the food-inks. Rhodamine B, phosphate buffered saline solution, and formaldehyde (37\%) were purchased from Sigma-Aldrich. The nozzles and barrels needed for 3D printing were obtained from Fisnar, Inc.

\subsection{Food-inks}

Stock solutions of $2 \% \mathrm{GG}(\mathrm{w} / \mathrm{v})$ and $40 \% \mathrm{WPI}(\mathrm{w} / \mathrm{v})$ were prepared by dispersion in deionized water. All solutions were used within $24 \mathrm{~h}$. WPI and GG were mixed in different proportions to obtain dispersions with varying concentrations. The mixtures contained from 0 to $2 \% \mathrm{GG}$ and from 0 to $20 \%$ WPI. Immediately after mixing, the dispersions were homogenized by vortexing at $3000 \mathrm{rpm}$ for $1 \mathrm{~min}$. To induce WPI and GG gelation of the samples, each was heated to $81{ }^{\circ} \mathrm{C}$ in a water bath until it had reached that same internal temperature and then was immediately cooled on ice.

\section{3. $3 D$ printing}

The influence of WPI\%, GG\%, flow rate\% (i.e., multiplier), printing speed, and nozzle diameter on the shape fidelity of the gels was studied by printing tests. Fig. 3 demonstrates the 3D printing setup, model, and fidelity factors analyzed in this study. A rectangular prism $(10 \mathrm{~mm}$ long $\times 10 \mathrm{~mm}$ wide $\times 5 \mathrm{~mm}$ tall) was designed with AutoCAD (version 2013) and exported as an STL file. The pathway and extrusion instructions for the 3D printer controller for each layer, i.e., G-code, were generated using the open-source CAM software Slic3r (version 1.2.9). The infill, fixed at $0 \%$ and two perimeters, was defined for the inside of the rectangular prism. The layer thickness, $\mathrm{Z}$ offset, and total number of layers were fixed as $70 \%$ of the nozzle diameter $(0.6,0.9$, and $1.2 \mathrm{~mm}$, respectively), as can be seen in Table SI4. The remaining variables were defined according to the DOE (Table SI5), except for the flow rate (\%), which was altered in the 3D printer display. Retraction was not considered for these studies. The G-code was uploaded to a Focus 3D Food Printer (byFlow). The 3D printing tests were performed by setting the initial nozzle height to zero (on the coverglass - see Fig. 3) and performing a priming extrusion immediately before running the test. All tests were performed at room temperature $\left(\sim 21^{\circ} \mathrm{C}\right)$. The fidelity of the 3D printed models was studied by measuring the dimensional fidelity of several variables $\left(\operatorname{Var} 3 D P_{i}\right)$ compared with the respective theoretical value determined by the sliced model $\left(\operatorname{VarSM}_{i}\right)$ - Table SI4. The variables analyzed included wall width (W), which was measured using a caliper, and angle $(\alpha)$ and height $(\mathrm{Z})$, which were analyzed using an image-based method based on a photo captured immediately after printing. The following equation was used to calculate the dimensional fidelity of each variable:

Fidelity $=\left(\frac{(\operatorname{Var} S M-\operatorname{Var} 3 D P) x 100}{\operatorname{VarSM}}\right)(\%)$

The best fidelity is represented as $0 \%$, whereas reduced or augmented dimensions result in negative or positive variations of a given initial dimension.

\subsection{Microstructure}

The gels were fixed in $10 \%$ formalin in phosphate-buffered solution (PBS) for $2 \mathrm{~h}$ at room temperature. Samples were washed with PBS and incubated in the dark for $1 \mathrm{~h}$ and $30 \mathrm{~min}$ while immersed in $0.2 \%(\mathrm{w} / \mathrm{v})$ Rhodamine B in PBS. The samples were extensively washed with PBS before mounting on glass slides with coverslips. Then, the samples were observed by confocal microscopy (Zeiss LSM 780) and excited at the wavelengths of 488 and $561 \mathrm{~nm}$. Emission was set at 570-620 nm for TPMT, and fluorescence observation was carried out with a $40 \times$ oil Zeiss objective. Images at different locations of the samples were recorded and analyzed using Fiji and the plugin ParticleSizer.

\subsection{Viscosity}

The viscosities of the GG and whey dispersions of the gelled solutions were measured using a rotational viscometer operated at $50 \mathrm{rpm}$ 
(HAAKETM Viscotester TM D). The measurements were repeated three times.

\subsection{Rheology}

Rheological measurements were performed using a DHR-1 hybrid rheometer (TA Instruments, USA). Flow curves were developed and dynamic oscillatory frequency analysis was performed using a stainless steel flat plate geometry $\left(40 \mathrm{~mm}, 2000 \mu \mathrm{m}\right.$ gap) at $25^{\circ} \mathrm{C}$. Flow curves were obtained using an up-down-up step-wise program with the shear rate ranging from 0.1 to $500 \mathrm{~s}^{-1}$. The flow curves were fitted to the Herschel-Bulkley model (Dervisoglu \& Kokini, 1986), which is given by: $\tau=\tau_{0}+K \dot{\gamma}^{n}$, where $\tau_{0}$ is the yield stress at zero shear rate (Pa.s), $K$ is the consistency coefficient $\left(P a . s^{n}\right.$ ), and $n$ is the flow behavior index (dimensionless).

Oscillatory dynamics rheology was performed in the linear viscoelastic region for frequency, non-isothermal, and structure recovery analyses. The frequency sweeps were carried out at $0.5 \%$ strain between 0.1 and $10 \mathrm{~Hz}$. Temperature ramps were performed to evaluate the gelation behavior. For this purpose, the rheometer was equipped with a stainless steel cone-plate geometry ( $50 \mathrm{~mm}, 2^{\circ}$ angle, $64 \mu \mathrm{m}$ truncation). The heating sweep was performed between $25^{\circ} \mathrm{C}$ and $81^{\circ} \mathrm{C}$ at $5{ }^{\circ} \mathrm{C} / \mathrm{min}$, $1 \mathrm{~Hz}$, and $0.5 \%$ strain. The samples were held at this temperature for 1 min and then were cooled to $25{ }^{\circ} \mathrm{C}$ under the same conditions. The samples were covered with a thin layer of silicone oil to avoid evaporation.

Structural recovery was evaluated after employing a non-isothermal method of analysis. The gelled systems were held at $25^{\circ} \mathrm{C}$ for $5 \mathrm{~min}$ and then submitted to a sudden shear $\left(100 \mathrm{~s}^{-1}\right.$ during $\left.1 \mathrm{~s}\right)$ to rupture the gelled network. Then, the elastic modulus $\left(G^{\prime}\right)$ was measured for $15 \mathrm{~min}$ to evaluate structural recovery. The elastic $\left(G^{\prime}\right)$ and viscous $\left(G^{\prime \prime}\right)$ moduli were evaluated, and the temperature gel point, i.e., phase transition, was determined by the crossover between $G^{\prime}$ and $G^{\prime \prime}$. All measurements were performed in triplicate.

\subsection{Shear stress model}

The 3D food printer is based on the concept of positive displacement, in which the force applied to extrude each food material depends on the flow rate dictated by the G-code, as well as on the rheological behavior of the food-inks in the presence of shear stress and the force limitation of the printing head $(400 \mathrm{~N})$. Based on rheology laws (Herschel-Bulkley, Rabinowitch Correction), fluid mechanics (Navier-Stokes, HagenPoiseuille, Bernoulli equation), the Slic3r flow rate equations $\left(\mathrm{Q}_{\text {slic3r }}\right)$, and conical nozzle shape, the force applied at the plunger can be estimated. See Supplementary Information II.

\subsection{Mass flow rate}

The full barrels were connected to a microfluidic flow controller (MFCTTM-EZ by Fluigent), and each mass extruded was weighed under a particular applied relative pressure. At least three samples were extruded for each pressure tested.

\subsection{Clustering}

Clustered heatmaps for the factors controlling printability and the main attributes of the printed inks were created using the Python (v3.7.0) package Seaborn (v0.9; https://seaborn.pydata.org). The raw data were normalized before analysis. Linear correlation coefficients were computed for every pair of factors, and clustered heatmaps were produced using the Seaborn cluster map function, which uses Euclidean distance metrics to generate a linkage matrix that can be used for hierarchical clustering.

\subsection{Statistical analysis}

The design of experiments (DOEs) and associated statistical analyses were performed using TIBCO Statistica ${ }^{\mathrm{TM}}$ (version 13). In all of the DOEs, the WPI concentrations in coded values were $1 \%(-1), 5.5 \%(0)$, and $10 \%(1)$. The GG concentrations for the coded values were $1 \%(-1)$, $1.25 \%(0), 1.5 \%(1)$.

\section{Results and discussion}

\subsection{Structuring of food-inks by phase separation}

By controlling the composition, the kinetics of phase separation, and the gelation mechanism of food-inks, a wide range of microstructures and textures can usually be designed using the principle of phase separation (Le et al., 2017; Turgeon et al., 2003; van de Velde et al., 2015; Wijaya et al., 2017). Herein, various WPI and GG solutions were homogenized and immediately heated/chilled to promote gelation. The process was monitored by rheology and end-point viscosity measurements of the solutions and gels. Viscosity is a valuable property determining the extrudability and shape stability of micro-extruded food-inks that are structured before printing.

Fig. SI1 shows the viscosity of the mixtures (and controls) before and after gelation. Whereas the viscosities of the solutions were, in general, less than 4.5 Pa s, after gelation, these values increased by factors of 7-10 $\times$. In contrast, the end-point viscosity of the sole GG solutions (1, 1.25 , and $1.5 \%)$ was less than 8 Pa s, while that for the WPI $(5,10$, and $15 \%)$ was less than $2 \mathrm{~Pa}$ s. This result indicates that the segregative phase separation of the biopolymers may be promoting a synergetic outcome. Moreover, the gelation was monitored by heating and cooling sweep tests performed between $25{ }^{\circ} \mathrm{C}$ and $81{ }^{\circ} \mathrm{C}$ and at $5{ }^{\circ} \mathrm{C} / \mathrm{min}, 1 \mathrm{~Hz}$, and $0.5 \%$ strain (Fig. SI2). The complex $\left(G^{*}\right)$, the viscous $\left(G^{\prime \prime}\right)$, and elastic $\left(G^{\prime}\right)$ moduli and the $\tan \delta$ were recorded. The $G^{*}$ indicates the total resistance to deformation, which considers both the $G^{\prime \prime}$ and $G^{\prime}$ material phases. The component $G^{\prime \prime}$, or loss modulus, is related to the viscous character, i.e., the energy dissipated with the flow of the material, whereas $G^{\prime}$, the storage or elastic modulus, correlates with the energy stored and released by the material returning to its original form upon load removal (stress fall-off). The ratio between both moduli, known as $\tan \delta\left(G^{\prime \prime} / G^{\prime}\right)$, indicates the prevalence of the elastic or viscous character (Larson, 1999).

During heating, the $G^{*}$ modulus reduced, and $\tan \delta$ increased, indicating a more liquid-like state. This behavior is attributed to GG fully hydrating accompanied by gelation initiation, which causes the structural coil transition to a double helix. At temperatures greater than 70 ${ }^{\circ} \mathrm{C}$, an increase in $G^{*}$ and a decrease in $\tan \delta$ in the presence of WPI was observed. Heating whey proteins promotes their unfolding and the exposure of free sulfhydryl groups on the globular proteins (i.e., $\beta$-lactoglobulin, $\alpha$-lactalbumin, and bovine serum albumin). This process creates monomers, disulfide-bonded dimers, trimers, and larger aggregates between the various proteins, forming a network (Havea et al., 2001; Puyol, Pérez, \& Horne, 2001; Shimada \& Cheftel, 1989). The temperature at which these molecular changes initiate depends on conditions such as ionic strength and $\mathrm{pH}$. This temperature can vary between $22{ }^{\circ} \mathrm{C}\left(\mathrm{pH} \mathrm{9,11)}\right.$ and $85{ }^{\circ} \mathrm{C}(\mathrm{pH}$ 3) (Monahan, German, \& Kinsella, 1995).

Continuous cooling diminished the tan $\delta$ to a value less than 1 , with a peak on the GG gel point at approximately $33-39{ }^{\circ} \mathrm{C}$ (Fig. SI3). A high protein content shifted the gel point toward its highest values. This behavior could be related to the presence of salts derived from the WPI (Meng, Hong, \& Jin, 2013) or the migration of water during the phase separation and gelation process. Indeed, previous reports have indicated that the gel point is affected by the polymer concentration, presence of salts, and pH (Kirchmajer, Steinhoff, Warren, Clark, \& In Het Panhuis, 2014; Miyoshi, Takaya, \& Nishinari, 1994; Picone \& Cunha, 2011). The obtained values are in agreement with those recorded for previously 
reported temperatures, i.e., 30 and $50{ }^{\circ} \mathrm{C}$ (Kirchmajer, Steinhoff, Warren, Clark, \& Het Panhuis, 2014; Miyoshi et al., 1994; Picone \& Cunha, 2011). Rheology confirmed the gelation of both the protein and polysaccharide components.

\subsection{Food-ink microstructure}

To better understand the impact of GG and WPI on the internal structure, the samples were stained with rhodamine B, which binds to the protein phase. The samples were also inspected by confocal microscopy (Fig. 1). The morphometric features were quantified by imagebased analysis, in the range of $1-15 \%$ for GG and $1-15 \%$ for WPI. The features of interest were: i) short axis length, ii) long axis length, iii) aspect ratio (long axis/short axis), iv) percentage of structures $\leq 5 \mu \mathrm{m}$ $(\% \leq 5 \mu \mathrm{m})$, v) percentage of structures $\leq 10 \mu \mathrm{m}(\% \leq 10 \mu \mathrm{m})$, vi) percentage of structures $\geq 25 \mu \mathrm{m}(\% \geq 25 \mu \mathrm{m})$, and maximum particle size detected (Max). Fig. SI4 contains the wafer graphs representing the average values of the previously mentioned features.

The confocal microscopy analysis (Fig. 1) confirmed the existence of two separated phases, i.e., a continuous GG phase enriched with WPI microstructures of different shapes: i) fibrillar, ii) packed beads forming fibrillar-like structures, or iii) beads.

The more extensive range morphological analysis revealed that the average lengths tended to increase when WPI $\geq 10 \%$ and GG $<1.5 \%$, reaching values as great as 7.8/10.3 $\mu \mathrm{m}$. For instance, $10 \%$ WPI $1 \%$ GG contained structures larger than $\geq 50 \mu \mathrm{m}$, and only $65 \%$ of the structures were smaller than $10 \mu \mathrm{m}$. Indeed, the maximum size extended beyond $120 \mu \mathrm{m}$ in one sample, $15 \%$ WPI $1.25 \%$ GG. In contrast, by reducing the WPI fraction to $1 \%$ and increasing GG to $1.5 \%$, food-inks with $94-97 \%$ of their structures smaller than $10 \mu \mathrm{m}$ and with average lengths of 2.5/ $4.6 \mu \mathrm{m}$ could be created. Those structures were also more elongated, as indicated by their increasing aspect ratio.
Moreover, in an attempt to model the effect of WPI and GG on the internal morphology, a more restricted range of WPI and GG concentrations (1-10\% and $1-1.5 \%$, respectively) was analyzed by employing a full factorial design (Table SI1). The obtained response curves are displayed in Fig. 1b) and c). The respective coefficients for the effect estimates, $\mathrm{R}^{2}$, and the mathematical models are shown in Tables S1.2 and SI3.

Regarding the design of experiments, most of the responses could not be modeled with a linear function due to the presence of a curved feature in the data, as identified by the data analysis in Table SI2. Nevertheless, the aspect ratio and the percentage of particles measuring more than 25 $\mu \mathrm{m}$ had a good fit (Table SI3). While the aspect ratio decreased and was only negatively related to the protein concentration, the presence of structures measuring more than $25 \mu \mathrm{m}$ could be increased by reducing the GG content and increasing the protein phase fraction.

Previous studies conducted with carrageenan $(0-0.6 \%)$ and whey protein $(13 \%)$ mixed to form heat-set gels showed that the microstructure could vary with the polymer and salt concentrations. The microstructures documented in this prior work could assume a protein continuous, bi-continuous, particulate, coarse stranded, or carrageenan continuous structure (Çakir \& Foegeding, 2011). In general, the mixed gels were composed of large particles of WPI, whose size could be reduced by including salt (e.g., $250 \mathrm{mM} \mathrm{NaCl}$ ). Interestingly, the same authors also reported that 5 of 6 mixed-gel combinations were discriminated in sensory texture analysis, highlighting the relevance of microstructure (Çakir et al., 2012). Another previous report on WPI beads in the serum phase of $5 \%$ WPI and $0.1 \%$ GG cold-set gels described these products as having a bi-continuous structure (van den Berg, Rosenberg, van Boekel, Rosenberg, \& van de Velde, 2009). A different work analyzed the formation of the microstructures of mixed cold-set whey protein with different polysaccharides (de Jong et al., 2009), including GG. With 3\% WPI and $0.04 \%$ GG, the authors obtained either a

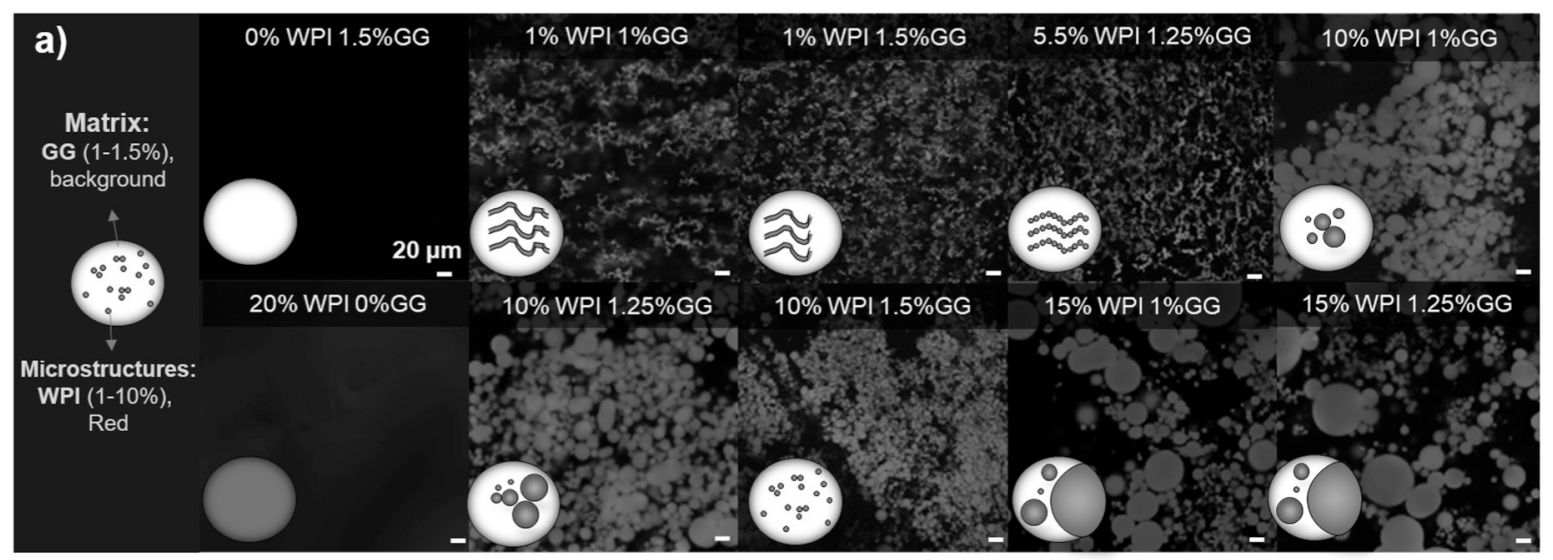

b)

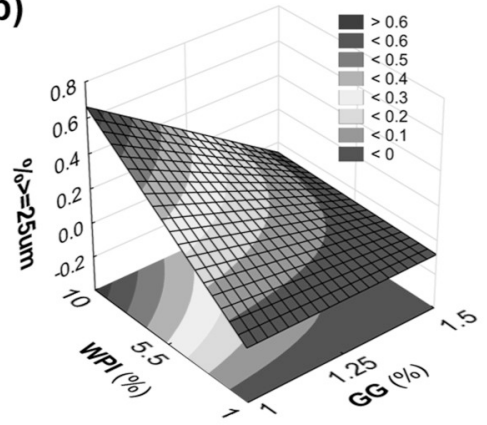

c)

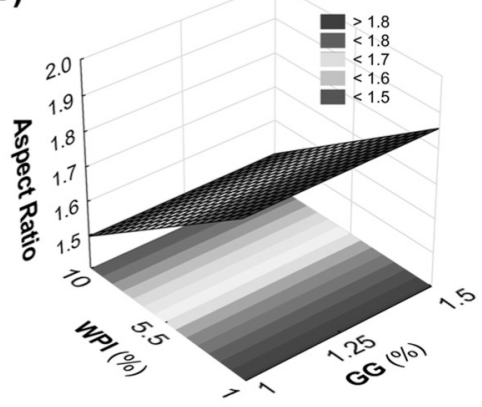

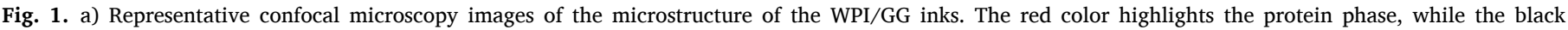

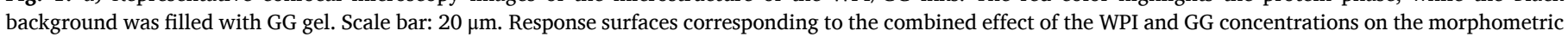

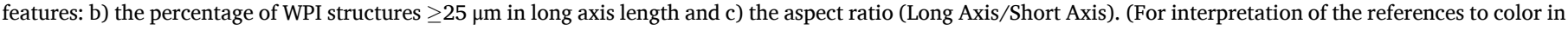
this figure legend, the reader is referred to the Web version of this article.) 
continuous or course-stranded protein microstructure varying with $\mathrm{pH}$ (4.8-7) or temperature $\left(6-45^{\circ} \mathrm{C}\right)$. None of the above-mentioned studies addressed the printability of these solutions, although the microstructure might be a determining factor. Even though the segregative phase separation was a central point of the prior studies considered here, in contrast the range of concentrations considered in the present work is different. Consequently, the biopolymers' viscosity ratios also varied. In the present study, GG had a significantly greater viscosity than WPI (up to 4 times greater), which likely contributed to establishment of the continuous GG microstructure that was generally observed. The higher that the viscosity difference between the two phases was, the lower value of shear required to promote drop breakup of the least viscous phase (Çakir et al., 2012), thereby resulting in a slightly more stable phase separation, which would have reduced the likelihood of obtaining bi-continuous or coarse-stranded structures.

\subsection{Study of printability}

\subsubsection{Screening printability by formulation}

An ideal food-ink could be deposited on a surface and any preceding layers at the flow rate determined by the slicing and print settings and in a manner that would not compromise the expected shape while allowing for high shape fidelity. Usually, such an ink is a viscous paste with a proper response to shear (i.e., shear-thinning with high recovery) or a low-viscosity ink (Ouyang, Highley, Sun, \& Burdick, 2017) structured in situ (Vancauwenberghe, Verboven, et al., 2018), printed in a supporting bath, e.g., FRESH technique(Hinton et al., 2015), or stabilized after deposition, e.g., coagulation bath (Sarker, Izadifar, Schreyer, \& Chen, 2018).

Researchers evaluate food-ink printability by several means, in particular, by before-printing techniques such as rheology, viscometry, extrusion force, and flowability (Kim et al., 2017; Z.; Liu, Zhang, et al., 2018). Printing tests can also be used, in which line, vase tests, or complex 3D structures are employed (Z. Liu, Bhandari, Prakash, Mantihal, \& Zhang, 2019; Severini, Derossi, \& Azzollini, 2016; Yang et al., 2018). In addition, although to a lesser extent, flow dynamics modeling can be used (Yang, Guo, Zhang, Bhandari, \& Liu, 2019). Kim et al. suggested a coding system to standardize the printability according to the structuring method, temperature, dimensional stability, and handling capability, based on a qualitative assessment of the actual 3D prints (Kim et al., 2017).

Sometimes researchers can struggle at the formulation stage, predominantly when important decisions are not made considering the most critical aspects of the food-ink. Herein, we suggest a manual approach to aid in the formulation and to evaluate printability (Fig. 2).

One milliliter of sample is sufficient for the quick, six-step assay. Step 1 - one can observe whether the ink is sufficiently cohesive while carrying out a freestanding extrusion. In general, higher cohesiveness and good flowability allow for more homogenous prints. The surface properties determine the adhesion of the first layer (e.g., roughness and surface tension) and dictate the successful build-up of the subsequent layers - step 2 . Then, by extruding a lattice, one can quickly examine the ink stability, e.g., if the center area is a square instead of more circular, as also suggested in previous works - step 3(Ouyang, Yao, Zhao, \& Sun, 2016). The fusion or distinction between the over-imposed lines is also indicative of shape stability - step 4. Finally, by successively depositing $100 \mu \mathrm{l}$ of ink on top of another $100 \mu \mathrm{l}$ (steps 5 and 6), one can progressively evaluate the self-supportiveness of the ink. A high capacity for self-support is essential for building up tall 3D food structures. The assay did not consider the effect of different flow rates; however, this analysis can be further automated and performed using a 3D printed and image-based measurement approach to achieve a precise evaluation. According to the criteria in Fig. SI5, a qualitative or numeric score can be attributed to each of the steps above.

We performed both qualitative and quantitative evaluations of our samples with increasing WPI and GG contents. Fig. SI6 displays representative images and qualitative results, and Fig. $3 \mathrm{c}$ reports the scores.

This assessment indicated that highly-printable food-inks should contain more than 1\% GG and up to a maximum of approximately $12 \%$ WPI. The samples with the highest scores were $5 \%$ WPI $1.75 \%$ GG and $10 \%$ WPI $1.5 \%$ GG, which scored 26 out of 26 .

Even though the samples with 15\% WPI could be sustained over imposed layers, the filaments were not homogenous, and consequently, the reduced resolution led to a score of less than 9. Large beads were present on the structure of those samples, as pointed out in the previous section, and the presence of aggregates might have diminished the ink's flowability. In contrast, the samples composed of fibrillar structures (i. e., with 1\% WPI) displayed an excellent flowability; however, the distinction between layers and their capacity to support height was not satisfactory. Thus, these multiscale inks might be more suitable for in situ crosslinking or may require further thickening. Overall, an excellent printability could be achieved by sufficiently increasing the viscosity of the GG continuous phase and/or increasing the WPI content up to approximately $12 \%$.

\subsubsection{DOE - optimization of printing according to composition and print settings}

The slicing settings establish the ink flow rate (e.g., layer thickness, printing speed, line width, or diameter), as shown in Fig. SII.1. The flow required and the specific fluid properties of the ink define the response to the extrusion shear, and the intrinsic rheology properties and recovery capacity of the ink determine the actual cross-section of the extruded shape in the printed filament. Therefore, optimizing a 3D food print should consider such intricate connections.

The printing was optimized based on the effect of five variables, and their interactions, on the dimensional fidelity of a double-walled void prism. A full factorial design was used to study the impact of the WPI and GG concentrations, flow rate \% (multiplier), printing speed, and nozzle diameter on the height $(\mathrm{Z})$, the angle $(\alpha)$, and the wall width $(\mathrm{W})$ variation in the sliced model. The printing tests were performed using the a)

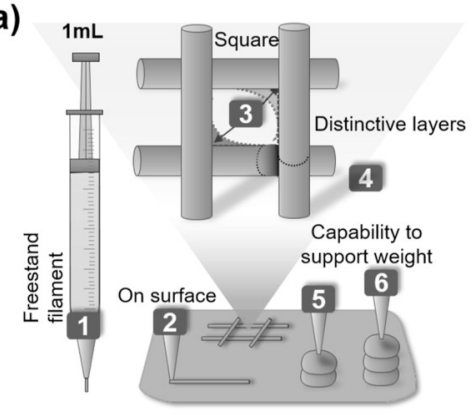

b)

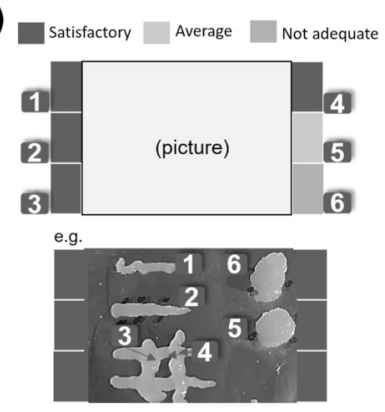

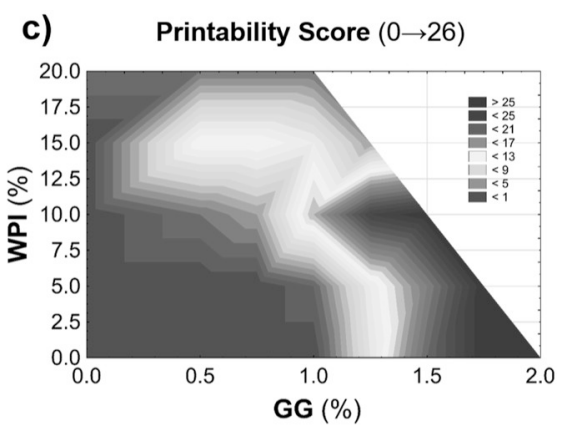

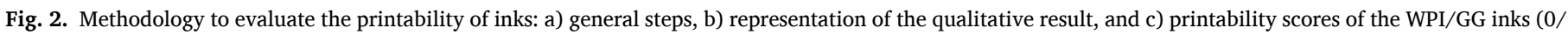

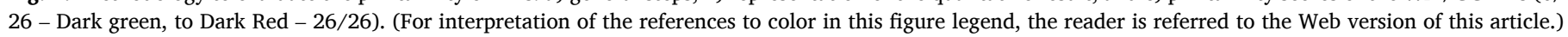




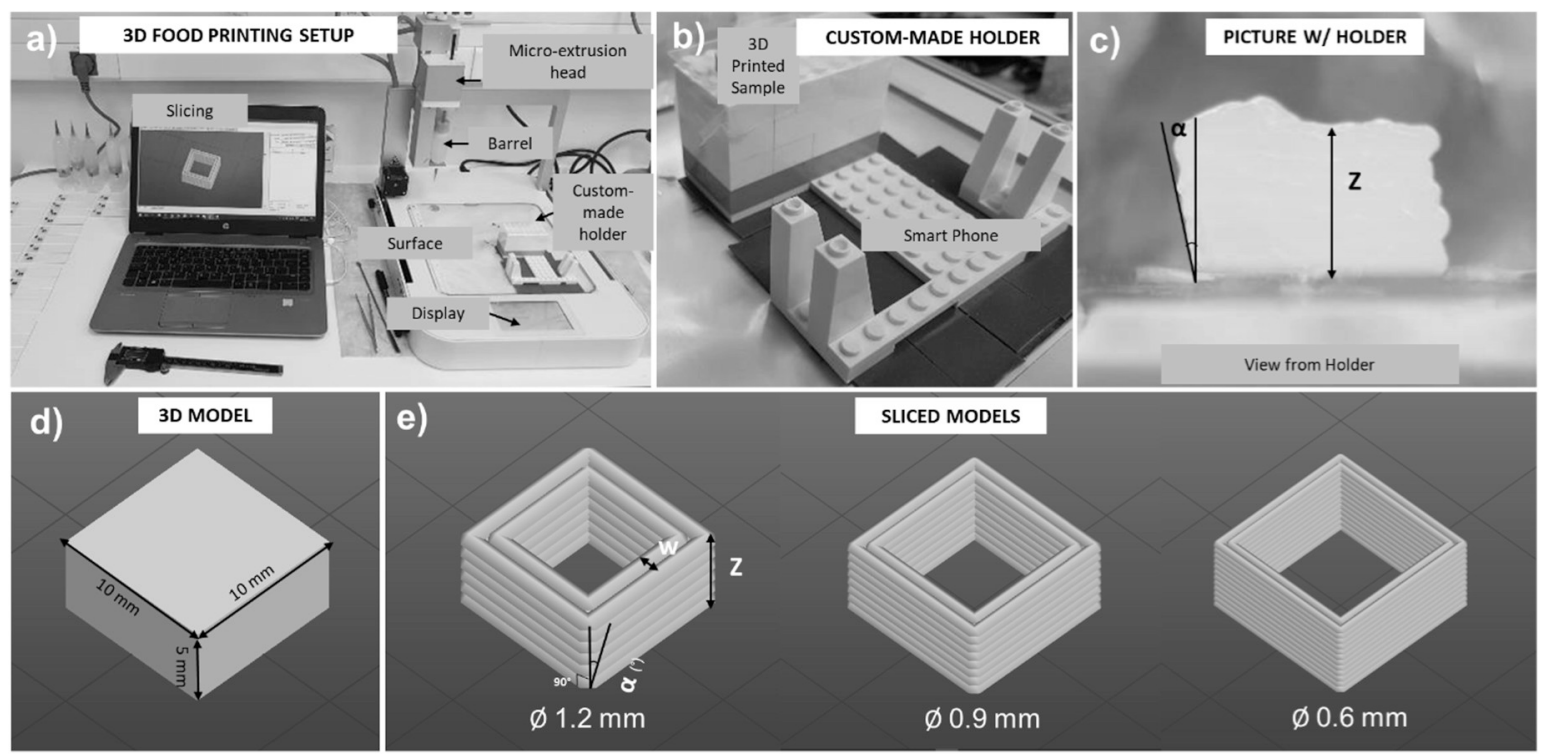

Fig. 3. 3D Food Printing Setup: a) 3D food printer, b) custom-made holder, c) example of an image used for analysis, d) 3D model, and e) sliced models for each of the three diameters used.

system and models displayed in Fig. 3 and Table SI4. Table SI5 shows the coded and natural values of the experiments, the output responses, and the respective coefficients for the effect estimates. The $\mathrm{R}^{2}$ values and the mathematical models for each response are given in Table SI6. The response surfaces of the most significant interactions are provided in Fig. 4 and Table SI7, in which the optimal print settings and composition are highlighted (white).

All of the variables influenced the height fidelity except the printing speed $(15-25 \mathrm{~mm} / \mathrm{s})$, which did not impact any of the responses analyzed. The estimates' coefficients of the principal effects on $\mathrm{Z}$ were positive (GG, WPI, diameter, and flow), while the combined effect of the diameter with the flow rate was $-15 \%$. The surface curve showed that the optimal height could be achieved over a wide range of concentrations (Fig. 4 a); however, specific diameters resulted in higher fidelity for particular ink compositions (Fig. 4 b).

Where the angle variation was close to zero, the ink was found to be capable of supporting the weight of the superimposed layers. The obtained model revealed that the differences tended toward positive values as the biopolymer's concentration, flow rate, and diameter were increased. At the same time, the coefficient of the combined effect of WPI and GG was negative ( $-22 \%)$. The surface curve clearly indicated that the most self-supportive food-inks had at least one of the biopolymers at its maximum concentration (Fig. 4 c). Indeed, at a low biopolymer content (1\%), the height significantly decreased, corroborating the previous printability assessments.

In contrast, the wall width was determined based on many secondand third-order interactions of the variables, although only the diameter had a significant, principal effect. Even though specific sliced models were made for each diameter, this factor still achieved an impact coefficient of $-160 /+160 \%$. The previous $\mathrm{Z}$ and wall width analysis had already directed the most promising biopolymer concentrations to specific combinations (i.e., 1 1, 1-1, -1 1, 1 0, 1 0; GG WPI, respectively). Furthermore, the best diameters and flow rates were selected for each of those combinations. The curves and their optimal ranges are highlighted in Fig. 4 c) and d) and Table SI7. According to the results, the proper combination of flow and nozzle can slightly improve the output. Although some combinations require high diameters and a reduced flow multiplier, nonetheless others provided suitable wall widths with small diameters, such as the case of $10 \%$ WPI 1\% GG (Fig. $4 \mathrm{~d}$ ).

A 3D spiral model was printed at $25 \mathrm{~mm} / \mathrm{s}$ with food-inks of different printability scores and a 1.2-mm nozzle (Fig. 5 a). The resulting quality correlated well with the printability score and the DOE equations. Increasing the amount of GG from $1.5 \%$ to $1.75 \%$, with $5.5 \%$ WPI, was sufficient to achieve a high score and proper representation of the 3D model, avoiding structural collapse. With 15\% WPI, the spreading was reduced but the topography of the structures was rough, leading to a reduced resolution. With intermediate concentrations, such as the case of $10 \%$ WPI $1.25 \%$ GG, a slight collapse was visible. Nevertheless, structures with both double walls and more than 10 layers of $840 \mu \mathrm{m}$ were printable at $25 \mathrm{~mm} / \mathrm{s}$ and stable (Fig. $5 \mathrm{~b}$ ).

\subsection{Rheological behavior: from flows curves to recovery}

Recent studies have indicated that specific rheological properties are essential and are more related to outcomes in certain printing stages than others (Z. Liu et al., 2019; Z. Liu, Zhang, et al., 2018; Paxton et al., 2017). In particular, here, the structural properties were measured at a low deformation rate, in the linear viscoelastic interval, before and after applying a high shear $\left(100 \mathrm{~s}^{-1}\right.$ for $\left.1 \mathrm{~s}\right)$. The food-ink extrusion stage was approximated to a large deformation test based on flow curves (0-500 $\mathrm{s}^{-1}$ ) and the Herschel-Bulkley rheology model (HB) (Joyner \& Daubert, 2017) The impact of various fluid and rheological properties was studied with full factorial design, employed within the previous ranges of concentrations (Table SI8). The surface curves in Fig. 6 a) and b), respectively, display the effect of the composition on the yield stress and viscosity recovery after $30 \mathrm{~s}$. The full results of the DOE of the remaining properties presented curvature and could not be correctly represented by a linear model. Full data can be found in Table SI8, with their analysis available in Table SI9 and corresponding models in Table SI10.

The viscoelastic properties measured at a low deformation shear $\left(G^{\prime}\right.$, complex viscosity, $\tan \delta$, yield stress) are related to the structure and its capacity to store or release energy, regarding the resting (before printing) and the post-recovery (after extrusion) stages. The complex viscosity, G', and the yield stress of the inks could be improved by increasing either the amount of GG or WPI, where their combination also had a synergistic effect (Fig. 6 a, Table SI9). They enhance the selfsupportiveness and height variation of the print by increasing its mechanical strength (Z. Liu et al., 2019; Z. Liu, Zhang, et al., 2018). In fact, the yield stress can be interpreted as the minimum shear/stress required to initiate material flow.

The $\tan \delta$ at the resting stage ranged from 0.199 to 0.119 , which indicates that the inks were elastic and structured fluids. Most of the inks 

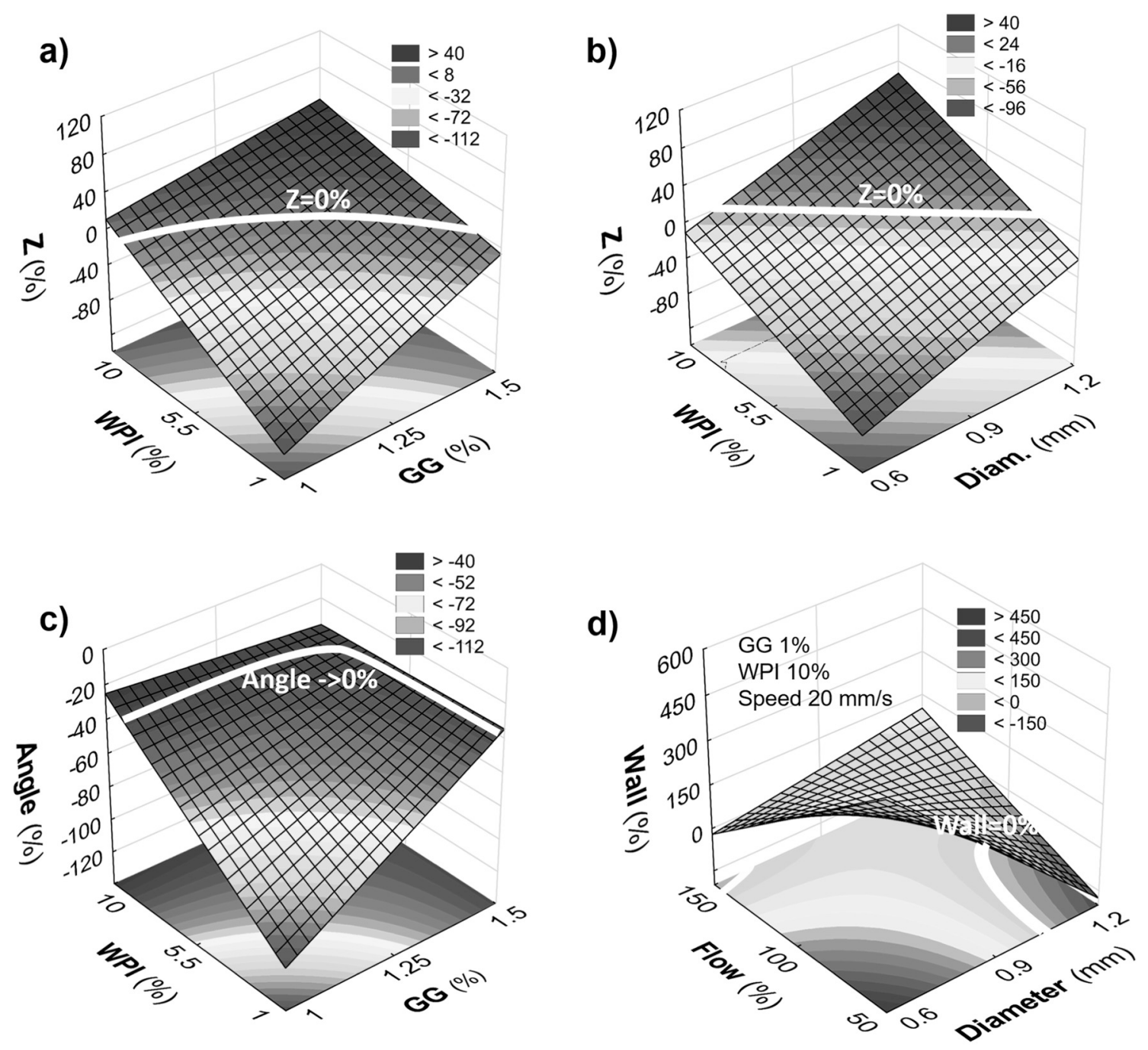

Fig. 4. Coded response surfaces corresponding to the combined effect of the: a) WPI and GG concentration on the height variation (Z \%); b) diameter and WPI \% on the Z \% (similar response to the case of diameter versus GG \%); c) WPI \% and GG \% on the angle variation; and d) flow rate and diameter on the wall width variation for $1 \%$ GG and $10 \%$ WPI. Where not specified, the other variables were fixed at the central point.

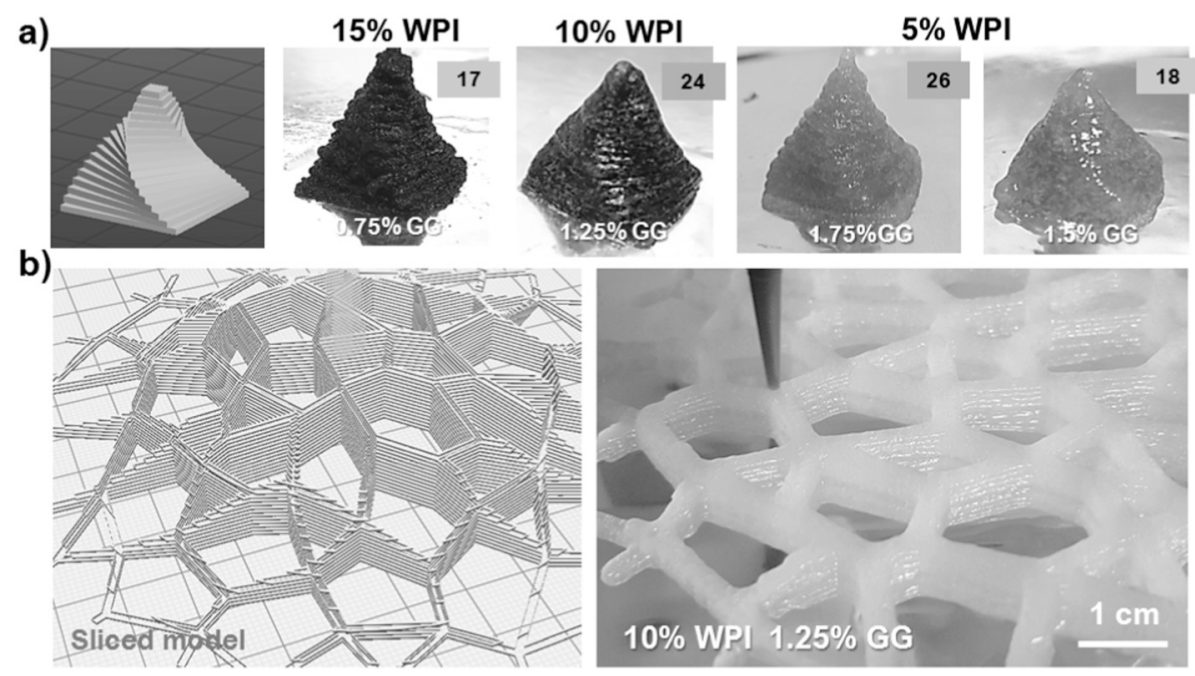

Fig. 5. Printing tests with WPI/GG inks: a) to build up a 3D spiral tower model with food-inks with different printability scores; b) large structure printed with $10 \%$ WPI $1.25 \%$ GG and a reduced flow rate (50\%), as suggested by the DOE results. All samples were printed at $25 \mathrm{~mm} / \mathrm{s}$ with a 1.2 -mm nozzle and sliced with a $0.84 \mathrm{~mm}$ layer thickness. 

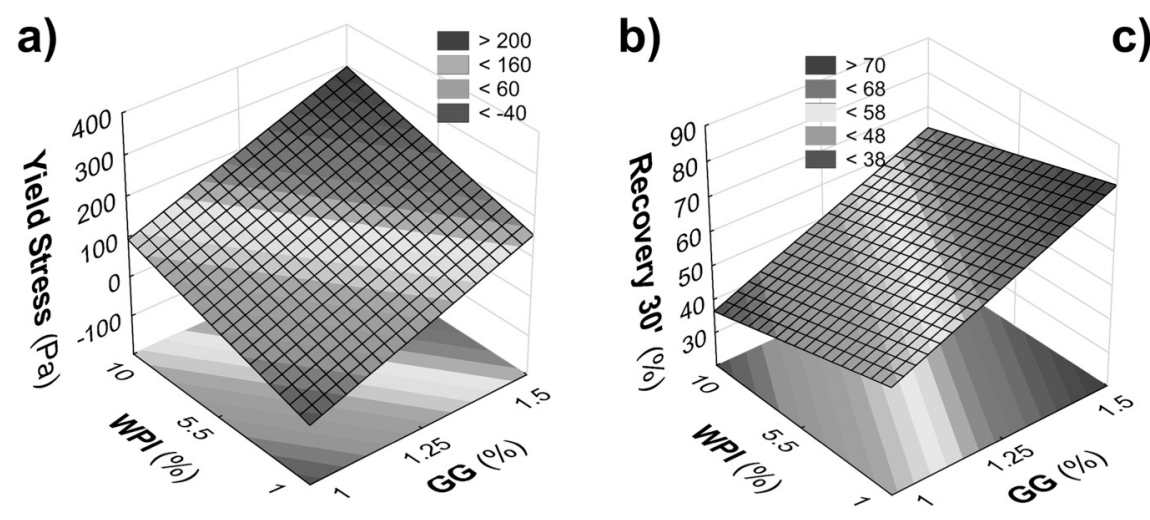

c)
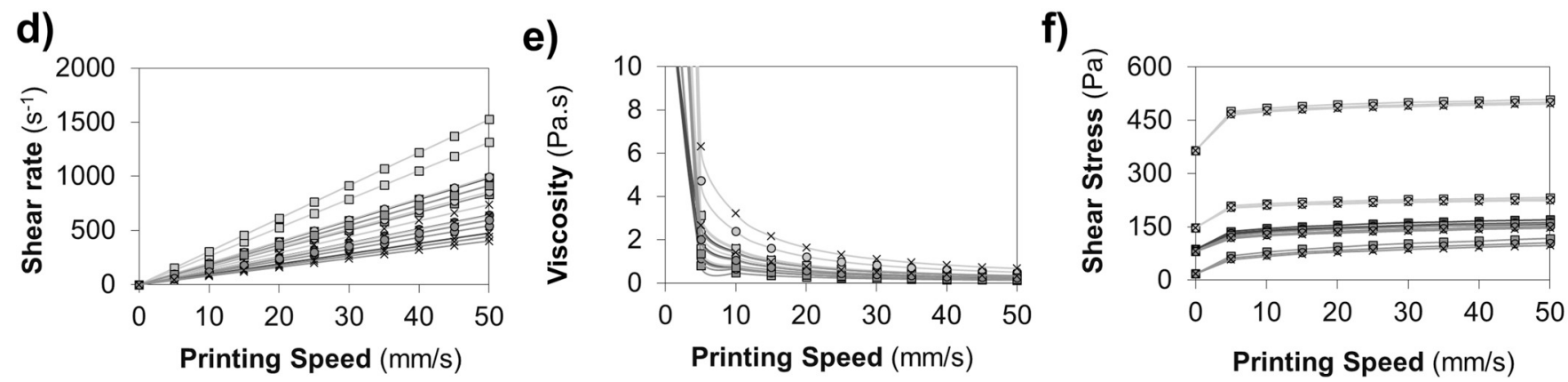

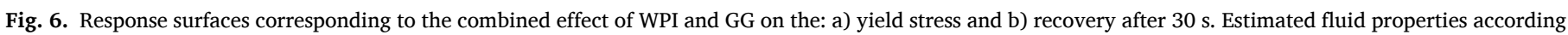
to the printing speed and the nozzle diameter, at the nozzle wall: c) legend of samples and diameters, d) shear rate, e) viscosity, and f) shear stress.

were weak gels with $0.1<\tan \delta<1$. In particular, the sample containing $10 \%$ WPI $1.5 \%$ GG $(\tan \delta=0.119)$ could be considered a prominent true and highly elastic gel due to its proximity to the true gel point ( $\tan \delta \leq$ 0.1 (van Vliet, 2013)). The recovering $\tan \delta$ (30 s) was slightly reduced (by $0.01-0.07$ ), and the stiffness and viscosity significantly decreased in some cases (e.g., $30 \%$ in the case of $10 \%$ WPI 1.5\% GG). Some of the samples recovered as much as $73 \%$ of their elastic features. Recovery was enhanced with GG, although a higher content of WPI had the opposite effect. This antagonism might be related to the different WPI microstructures (Fig. 1). Recovery diminished with increasing structural dimensions to $\geq 25 \mu \mathrm{m}(0.8 \%)$ or with the reduction of particles $\leq 5 \mu \mathrm{m}$ (20\%) and $10 \mu \mathrm{m}(60 \%)$.

The shear stress and shear rate parameters set in the flow curve test were fitted with the three-parameter rheological HB model, to extract the intrinsic and large deformation properties of the fluids, i.e., HB yield stress, consistency coefficient $(K)$, and flow index $(n)$.

The flow index varied between 0.12 and 0.3 , which points out the strong shear-thinning profile of the WPI/GG phase-separated inks (Table SI8). Such a flow index is desirable because it translates into a more pronounced decrease in viscosity that facilitates the extrusion process, reducing the force required. Nevertheless, a significant fraction of such a decrease in viscosity should be recovered to avoid the spreading of the ink and weak shape stability (Abbadessa, Landín, Oude Blenke, Hennink, \& Vermonden, 2017; Derossi, Caporizzi, Azzollini, \& Severini, 2018; Paxton et al., 2017).

The shear rate selected for the recovery test mentioned above was based on literature reports. Values between 30 and $100 \mathrm{~s}^{-1}$ are frequently considered, independently of the material used (Abbadessa et al., 2017; Derossi et al., 2018; Feilden, Blanca, Giuliani, Saiz, \& Vandeperre, 2016; Schaffner, Rühs, Coulter, Kilcher, \& Studart, 2017). However, the actual shear rate at the nozzle depends on the rheological properties and the print flow rate, as defined by the Rabinowitch correction of shear stress at the wall for non-Newtonian fluids (Equation 5 SII).

Based on well-established analytical models, i.e., the Rabinowitch correction of shear stress at the wall, Herschel-Bulkley model, and Hagen-Poiseuille equation, one can estimate the fluid properties according to the slicing, print settings, and rheology properties (Support Information II). The models consider no flow at the nozzle/barrel wall due to adhesion, whereas the shear is high at the wall and zero at the center. Consequently, the decrease in deformation and viscosity is high, and the shear rate is low near the walls (Blaeser et al., 2016). Additional effects such as the material slipping at the wall (i.e., fluid velocity at the wall $\neq 0$ ) and entrance and exit effects (e.g., expansion) can slightly alter the actual shear stress at the wall. The effects of these phenomena can be further considered by the Mooney (Bekkour, 1999; de Vargas, Pérez-González, \& de J. Romero-Barenque, 1993) and the Bagley (Barakos \& Mitsoulis, 1995) corrections.

The impact of the food-ink, the printing speed $(15-25 \mathrm{~mm} / \mathrm{s})$, and the nozzle (0.6-1.2 mm) were estimated (Fig. SI7). In Fig. $6 \mathrm{c}$ ) to f), the fluid behavior of the inks at the wall is shown, as well as across the nozzle section in Fig. II3 for the case of 10\%WPI 1.5\% GG. The shear rate at the wall significantly increased with the printing speed and increased even more significantly when the nozzle diameter was reduced. The high shear-thinning capacity (lower $\mathrm{n}$ ) promptly decreased the viscosity as the speed was increased, allowing the material to deform significantly near the wall and at relatively small shear stresses. For the previously mentioned sample, the shear rates were in the range of $200-800 \mathrm{~s}^{-1}$, while the viscosity at the wall decreased from 2.2 to 1.3 Pa s, representing stress between 480 and $496 \mathrm{~Pa}$.

The actual shear rates in the test, by the extrusion stage, can vary from 100 to $800 \mathrm{~s}^{-1}$. Those values are significantly higher than the frequently considered value of $100 \mathrm{~s}^{-1}$, which highlights the importance of these estimations when a more accurate recovery analysis is intended.

Overall, the viscosity and the shear stress at the wall were only slightly altered as the speed was increased to $50 \mathrm{~mm} / \mathrm{s}$. The observation that speed has minimal influence on these parameters corroborates with the DOE results, which also indicated that speed has little effect on the shape fidelity when printing between 15 and $25 \mathrm{~mm} / \mathrm{s}$.

These estimates suggest that with phase-separated inks, one might 
reliably print at speeds as great as $50 \mathrm{~mm} / \mathrm{s}$, or even higher at low shear stress $(<500 \mathrm{~Pa})$. Transposing this capacity to other food-inks might increase the commercial viability of micro-extrusion-based 3D printing, especially for food printing and bioprinting. Developing low shear stress food-inks is essential for future cell-based edible products. Cell viability is jeopardized by the high shear stress (Blaeser et al., 2016), which can further compromise the functionality or quality of those products. Examples are cell-based meat products, printed probiotic-rich foods, or edible foods containing plant-derived cells, where further cell growth or maturation might be required.

\subsection{Correlations between composition, microstruture, rhelogy, and $3 D$ printing}

The 3D printing of edible structures with adequate shape fidelity depends on a variety of ink properties, on the extrusion and deposition behaviors, and the post-processing conditions. This complexity and the existence of a broad spectrum of variables with very intricate relationships create complexity when trying to predict printability and shape fidelity, in particular, in the case of complex and third-body systems, such as the case of phase-separated inks.

Herein, by heat-map clustering, the correlation factors between the following variables and properties were determined (Fig. 7). The categories and respective properties that were analyzed included:

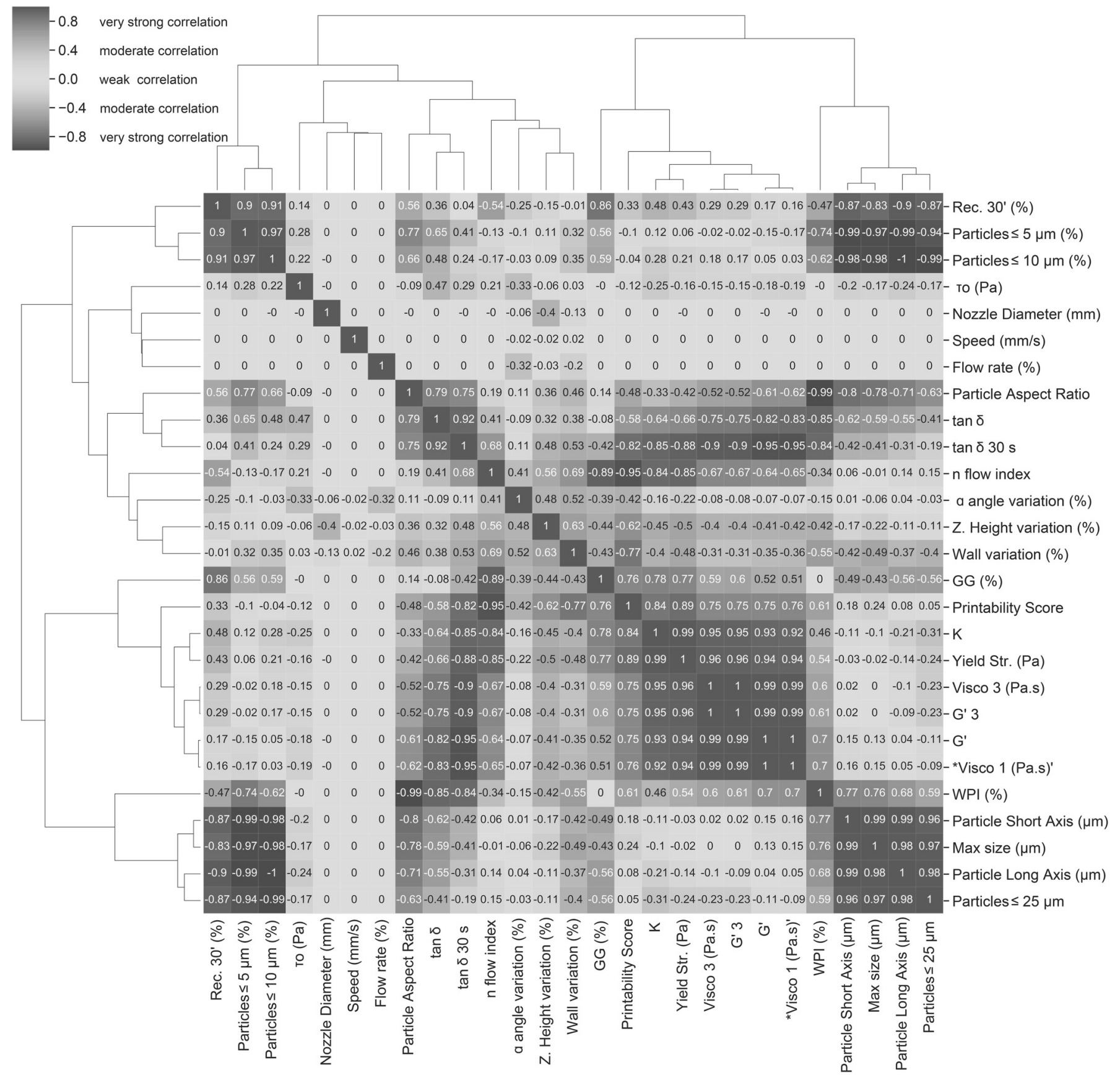

Fig. 7. Clustered heat-map for the factors that control the printability and the main attributes of the printed inks in the range $1-1.5 \%$ GG and $1-10 \%$ WPI. Red color indicates a positive correlation, while blue color indicates a negative correlation. (For interpretation of the references to color in this figure legend, the reader is referred to the Web version of this article.) 
microstructure (Particle Short Axis, Particle Long Axis, Particle Aspect Ratio, $\%$ particles $\leq 5 \mu \mathrm{m}$; \% particles $\leq 10 \mu \mathrm{m}$; \% particles $\geq 25 \mu \mathrm{m}$; Max Size); rheology/texture (Yield Stress, $\tau_{0}$; $\tan \delta$; $\tan \delta 30$; flow index, $n$; consistency index, $K$; resting complex viscosity, *Visco 1 ; complex viscosity after recovery, "Visco 3 ; resting storage modulus, $G$ '; storage modulus after recovery, $G^{\prime} 3$; Recovery 30 '); printability (printability score); print settings (Nozzle Diameter; Speed; Flow multiplier), composition (GG \%; WPI \%), and shape fidelity (angle variation, $\alpha$; double wall width variation, $\mathrm{W}$; height variation, $\mathrm{Z}$ ).

The heat-map is color-coded with blue and red in varying intensities. Blue indicates a negative correlation, while red denotes a positive relationship, and the increasing insensitivity indicates an increase in the correlation factor. The factors are considered either very weak (0.-0.19), weak (0.2-0.39), moderate (0.4-0.59), strong (0.6-0.79), or very strong $(0.8-1.0)$ as linear relations. Several strong and very strong correlations were detected and are further discussed in the following.

Both biopolymers influenced the rheological and fluid properties of the inks, which resulted in several strong correlations. However, these same properties had different relationships to the remaining properties. Interestingly, while WPI had a very strong/strong linear relation with microstructure (e.g., \% Particles $\leq 5 \mu \mathrm{m},-0.74$; Aspect ratio, -0.99 ), $\tan \delta(-0.84)$, and a factor of 0 for recovery, GG had a very strong correlation with the recovery 30 ' $(0.86)$ and flow index $(-0.89)$. Indeed, the recovery percentage seemed to be predictable by the content of small particles $(0.9,0.91)$.

The printability score had a weak/positive relationship with the recovery $(0.33)$, a moderate negative correlation with the aspect ratio $(-0.48)$, and in general, no significant linear relationship with morphology. However, the printability test had very strong/strong correlations with several other factors, specifically, the rheological/ texture and fluid properties. These correlations were: $\tan \delta 30 \mathrm{~s}(-0.82)$, flow index $(-0.95)$, consistency index $(0.84)$, yield stress $(0.89), G$ ' (0.75), and complex viscosity (0.75).

The correlation factors with the 3D printing settings were, in general, very weak, except for some moderate correlations with shape fidelity. Following the DOE analysis, it was already observed that the responses depended on second- and third-order interactions between the variables

\subsection{Printability window of the $3 D$ food printer}

The viscosity and hardness of the inks can improve the shape fidelity of the 3D print; however, when the consequent extrusion force is too high or reaches the limit of the 3D printer, the process is compromised (Z. Liu, Zhang, et al., 2018; Postiglione, Natale, Griffini, Levi, \& Turri, 2015). Performing extrudability tests is one alternative, although modeling the behavior of inks in the printing head can reduce experimentation and give insight regarding the best route for formulation improvement.

A few studies have employed analytical flow dynamics, contact angle, and rheology models to assess shape stability. Göhl et al. (Göhl et al., 2018) were able to predict the fluid properties, width, and height fidelity of the printed filaments of nano-fibrillar cellulose bio-inks. Blaeser et al. (Blaeser et al., 2016) predicted the average flow rate and shear stress inside the nozzle over time for different nozzles and low-viscosity inks when using a pressure-controlled, microvalve-based printing head. Moreover, Suntornnond et al. (Suntornnond, Tan, An, \& Chua, 2016) proposed a simple model to predict the printed filament width based on the nozzle size, pressure, and printing speed for pneumatic extrusion-based bioprinting. The authors combined the power law, pressure decrease, and Rabinowicht correction of shear rate. The model did not consider the pressure decrease related to friction and geometry, which can alter the pressure at the nozzle and is highly affected by the printing speed and fluid behavior.

Herein, we tried to estimate the extrusion force based on the slicing/ print settings (i.e., nozzle diameter, layer height, line width, and speed), rheology model, flow dynamics, and energy conservation principles, considering the decreases in pressure at the different sections of the printing head (see Supplementary Information II). Fig. 8 a) shows the printing head geometry and general energy conservation equations for the different sections. Based on the previous analysis and the Bernoulli equation for a steady flow, the pressure energy, the kinetic energy, the potential energy, and the energy losses, the extrusion force at the plunger was estimated by Equation 1:

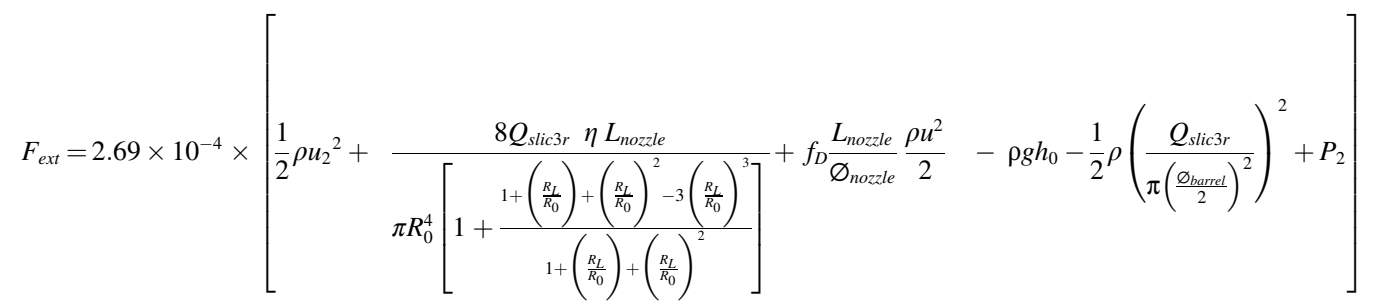

and, therefore, could not be correctly represented by a linear relation. Nevertheless, the $\mathrm{Z}$ and wall factors had, respectively, moderate (0.62) and strong (0.77) correlations with the printability score.

As observed previously, the highest scores were attained with structured fluids of high shear-thinning behavior and hardness/viscosity. Actually, there was very strong evidence that increasing the content of protein reduced the aspect ratio and the particle size, increasing the 3D structuration of the ink (i.e., $\tan \delta$ reduction). Increasing the GG fraction augmented the shear-thinning behavior of the inks, and consequently, additions of both biopolymers were found to improve its recovery capacity. However, at values greater than $12 \%$ WPI, the maximum size increased, and the printability score decreased due to the formation of a solid gel structure. Furthermore, the printability test might predict the rheological and, at least some, texture properties (e.g., hardness and thickness).
The variables in Equation 1 are $R$, the nozzle diameter $(m) ; f_{D}$, the Darcy factor; $\mathrm{L}_{\text {nozzle }}(\mathrm{m})$, the nozzle length $(\mathrm{m}) ; \eta$, the viscosity at the nozzle exit at the wall (Pa.s); $\rho$, ink density $\left(\mathrm{Kg} / \mathrm{m}^{3}\right) ; \mathrm{Q}_{\text {slic3r }}$, the flow rate calculated by Silc3r $\left(\mathrm{m}^{3} / \mathrm{s}\right) ; \mathrm{R}_{0}$, the nozzle diameter at the entrance (approximate barrel radius at the exit) $(\mathrm{m}) ; \mathrm{R}_{\mathrm{L}}$, the nozzle diameter at the exit $(=\mathrm{R})(\mathrm{m}) ; \mathrm{u}_{0}$, the ink speed in the barrel $(\mathrm{m} / \mathrm{s}) ; \mathrm{u}_{1}$, the flow speed at the exit of the barrel $(\mathrm{m} / \mathrm{s}) ; \mathrm{u}_{2}$, the speed at the exit of the nozzle $(\mathrm{m} /$ $\mathrm{s})$; and $\mathrm{h}_{0}$, the height of the food-ink in the barrel (m).

The calculations indicated that the absolute force at the plunger during the printing tests ranged from 28 to $40 \mathrm{~N}$, confirming that the tests were performed within the safety limit (less than $400 \mathrm{~N}$ ), as shown in Fig. 8 b). The extrusion force increased when reducing the nozzle diameter or increasing the print speed. From the model, one can also determine that a pressure of $1.45-1.48$ bar might be sufficient to extrude $0.1-0.6 \mathrm{ml} / \mathrm{min}$ of $10 \%$ WPI $1.5 \%$ GG $(0.6 \mathrm{~mm}, \sim 8.25 \mathrm{~mm} / \mathrm{s}$ to $50 \mathrm{~mm}$ / 
a)

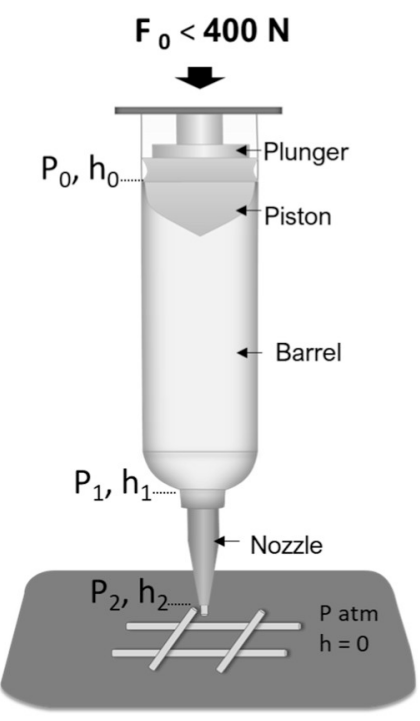

BARREL to NOZZLE

$P_{0}+\rho g h_{0}+\frac{1}{2} \rho u_{o}^{2}$

$=P_{1}+\rho g h_{1}+\frac{1}{2} \rho u_{1}^{2}+\Delta P_{\text {barrel }}$

$+\Delta P_{\text {friction barrel }}$

\section{NOZZLE to EXIT}

$P_{1}+\rho g h_{1}+\frac{1}{2} \rho u_{1}^{2}+\Delta P_{\text {barrel }}+$

$\Delta P_{\text {friction barrel }}$ b)

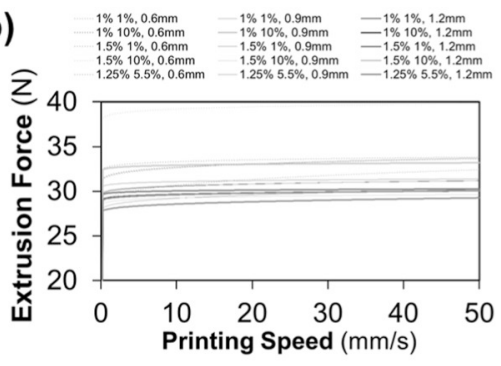

Force abs $(\mathrm{N})$

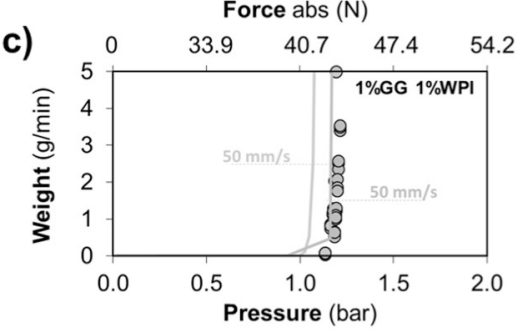

Force abs (N)
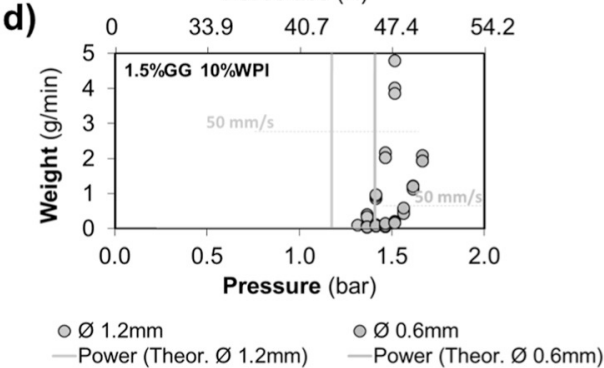

Fig. 8. a) Schematic representation of the effect of the flow dynamics on the micro-extrusion plunger/ piston-driven printing head. $P_{n}$ is the pressure, $\rho g h_{n}$ is the potential energy, $\frac{1}{2} \rho u_{n}^{2}$ is the kinetic energy, $\Delta P_{\text {shape }}$ is related to pressure loss due to geometry (barrel or nozzle), and. $\Delta \boldsymbol{P}_{\text {friction }}$ is the head loss due to friction. b) Extrusion force at the plunger according to the printing speed, calculated based on Equation (2). Mass flow rate according to the absolute pressure applied for a nozzle diameter of 0.6 or $1.2 \mathrm{~mm}$ : c) $1 \%$ WPI $1 \%$ GG and d) $1.5 \%$ GG $10 \%$ WPI. Yellow and green lines point to the mass flows required for a printing speed of $50 \mathrm{~mm} / \mathrm{s}$. . (For interpretation of the references to color in this figure legend, the reader is referred to the Web version of this article.) s). A less viscous ink, i.e., $1 \%$ WPI $1 \%$ GG, would be extruded with a pressure between 1.13 and 1.2 bar. Such pressures are within the range of pressures reported for cellulose-based inks (Göhl et al., 2018): 1.15 bar for $0.1 \mathrm{ml} / \mathrm{min}$ of nano-fibrillar cellulose/alginate or $1.41 \mathrm{bar}$ for $4 \%$ nano-fibrillar cellulose at $0.09 \mathrm{ml} / \mathrm{min}$ (diameter of $0.42 \mathrm{~mm}$ ).

The model validation was performed with the most and least viscous inks. By using a pressure controller, the mass and corresponding flow rate were related to the actual pressure required. In Fig. $8 \mathrm{c}$ ) and d), the theoretical and actual flow masses of the two inks are presented according to the pressure applied and equivalent absolute force at the plunger.

The actual relative pressure shifted $0-0.25$ bar relative to the theoretical models. Such variations might have originated from small differences in the fluid properties (HB constants) of the gels prepared in the barrel versus gelled in situ in the rheometer. Another hypothesis is the existence of friction between the small contact lines of the plunger and the barrel. Nevertheless, the actual force at the plunger varied less than $7 \mathrm{~N}$. It was also confirmed that these samples could be easily extruded at the flow rates required for speeds greater than $50 \mathrm{~mm} / \mathrm{s}$. Indeed, the ink $10 \%$ WPI $1.5 \%$ GG seemed to have resilient stability that was independent of the pressure applied.

\section{Conclusion}

WPI/GG inks were characterized in terms of microstructure, rheological properties, printing performance, clustering analysis of variables and outputs, and extrusion force.

Overall, increasing the protein content reduced the aspect ratio and WPI particle size in the GG matrix. At the same time, the 3D structuration of the ink was increased ( $\tan \delta$ reduction). In contrast, increasing the GG fraction augmented the shear-thinning behavior of the inks, and consequently, both GG and WPI were found to improve the shear recovery capacity. To achieve high fidelity, at least one of the biopolymers should be used, in a fraction greater than $5.5 \%$, for the case of WPI, or greater than 1.25 , for the case of GG\%. As an alternative, the printability of low viscosity inks may be improved by performing in situ cross-linking (e.g., $\mathrm{CaCl}_{2}$ ). The results also suggested that the least $(1 \%$ WPI) and most viscous (10\% WPI) inks could be printed/extruded at high speed $(>25 / 50 \mathrm{~mm} / \mathrm{s})$ by applying low extrusion forces $(<50 \mathrm{~N})$ and low shear stresses $(<500 \mathrm{~Pa})$. However, at fractions greater than $12 \% \mathrm{WPI}$, the maximum particle size increased, and the printability score decreased due to the formation of a solid gel structure. In addition, the printability test might predict rheological and, at least some, texture properties (e.g., hardness and thickness), once automated.

\section{CRediT authorship contribution statement}

Sara M. Oliveira: Conceptualization, Methodology, Investigation, Formal analysis, Visualization, Writing - original draft. Luiz H. Fasolin: Methodology, Investigation. António A. Vicente: Supervision, Writing review \& editing. Pablo Fuciños: Conceptualization, Writing - review \& editing. Lorenzo M. Pastrana: Conceptualization, Writing - review \& editing, Supervision, Funding acquisition.

\section{Acknowledgments}

This work was supported by the Nanotechnology-based functional solutions project, funded by ERDF and CCDR-N, under the call Norte2020 (Ref. NORTE-01-0145-FEDER-000019) and Enhance Microalgae (High added-value industrial opportunities for microalgae in the Atlantic Area), funded by ERDF, under the Call Interreg Atlantic Area 2014-2020 (Ref. EAPA_338/2016). 


\section{Appendix A. Supplementary data}

Supplementary data to this article can be found online at https://doi. org/10.1016/j.foodhyd.2020.106120.

\section{References}

Abbadessa, A., Landín, M., Oude Blenke, E., Hennink, W. E., \& Vermonden, T. (2017). Two-component thermosensitive hydrogels: Phase separation affecting rheological behavior. European Polymer Journal, 92, 13-26. https://doi.org/10.1016/j. eurpolymj.2017.04.029.

Bajaj, I. B., Survase, S. A., Saudagar, P. S., \& Singhal, R. S. (2007). Gellan gum: Fermentative production, downstream processing and applications. Food Technology and Biotechnology, 45(4), 341-354.

Barakos, G., \& Mitsoulis, E. (1995). Numerical simulation of extrusion through orifice dies and prediction of Bagley correction for an IUPAC-LDPE melt a). Journal of Rheology, 39(1), 193-209. https://doi.org/10.1122/1.550700.

Barbut, S., \& Foegeding, E. A. (1993). Ca2+-Induced gelation of pre-heated whey protein isolate. Journal of Food Science, 58(4), 867-871. https://doi.org/10.1111/j.13652621.1993.tb09379.x.

Bekkour, K. (1999). Evaluation of slip effects in the capillary flow of foams. Applied Rheology, 9(1), 10-16.

van den Berg, L., Rosenberg, Y., van Boekel, M. A. J. S., Rosenberg, M., \& van de Velde, F. (2009). Microstructural features of composite whey protein/polysaccharide gels characterized at different length scales. Food Hydrocolloids, 23(5), 1288-1298. https://doi.org/10.1016/j.foodhyd.2008.10.013.

Blaeser, A., Duarte Campos, D. F., Puster, U., Richtering, W., Stevens, M. M., \& Fischer, H. (2016). Controlling shear stress in 3D bioprinting is a key factor to balance printing resolution and stem cell integrity. Advanced Healthcare Materials, 5 (3), 326-333. https://doi.org/10.1002/adhm.201500677.

Boye, J. I., Alli, I., Ismail, A. A., Gibbs, B. F., \& Konishi, Y. (1995). Factors affecting molecular characteristics of whey protein gelation. International Dairy Journal, 5(4), 337-353. https://doi.org/10.1016/0958-6946(94)00012-E.

Çakir, E., Daubert, C. R., Drake, M. A., Vinyard, C. J., Essick, G., \& Foegeding, E. A. (2012). The effect of microstructure on the sensory perception and textural characteristics of whey protein/к-carrageenan mixed gels. Food Hydrocolloids, 26(1), 33-43. https://doi.org/10.1016/j.foodhyd.2011.04.011.

Çakir, E., \& Foegeding, E. A. (2011). Combining protein micro-phase separation and protein-polysaccharide segregative phase separation to produce gel structures. Food Hydrocolloids, 25(6), 1538-1546. https://doi.org/10.1016/j.foodhyd.2011.02.002.

Derossi, A., Caporizzi, R., Azzollini, D., \& Severini, C. (2018). Application of 3D printing for customized food. A case on the development of a fruit-based snack for children. Journal of Food Engineering, 220, 65-75. https://doi.org/10.1016/j. jfoodeng.2017.05.015.

Dervisoglu, M., \& Kokini, J. L. (1986). Steady shear rheology and fluid mechanics of four semi-solid foods. Journal of Food Science, 51(3), 541-546.

Dick, A., Bhandari, B., \& Prakash, S. (2019). 3D printing of meat. Meat Science, 153, 35-44. https://doi.org/10.1016/j.meatsci.2019.03.005.

Esquena, J. (2016). Water-in-water (W/W) emulsions. Current Opinion in Colloid \& Interface Science, 25, 109-119. https://doi.org/10.1016/j.cocis.2016.09.010.

Feilden, E., Blanca, E. G. T., Giuliani, F., Saiz, E., \& Vandeperre, L. (2016). Robocasting of structural ceramic parts with hydrogel inks. Journal of the European Ceramic Society, 36(10), 2525-2533. https://doi.org/10.1016/j.jeurceramsoc.2016.03.001.

Godoi, F. C., Prakash, S., \& Bhandari, B. R. (2016). 3d printing technologies applied for food design: Status and prospects. Journal of Food Engineering, 179, 44-54. https:// doi.org/10.1016/j.jfoodeng.2016.01.025.

Göhl, J., Markstedt, K., Mark, A., Håkansson, K., Gatenholm, P., \& Edelvik, F. (2018). Simulations of 3D bioprinting: Predicting bioprintability of nanofibrillar inks. Biofabrication, 10(3), 34105. https://doi.org/10.1088/1758-5090/aac872.

Havea, P., Singh, H., \& Creamer, L. K. (2001). Characterization of heat-induced aggregates of $\beta$-lactoglobulin, $\alpha$-lactalbumin and bovine serum albumin in a whey protein concentrate environment. Journal of Dairy Research, 68(3), 483-497. https:// doi.org/10.1017/S0022029901004964.

Hinton, T. J., Jallerat, Q., Palchesko, R. N., Park, J. H., Grodzicki, M. S., Shue, H. J., et al. (2015). Three-dimensional printing of complex biological structures by freeform reversible embedding of suspended hydrogels. Science Advances, 1(9). https://doi. org/10.1126/sciadv.1500758. e1500758.

de Jong, S., Klok, H. J., \& van de Velde, F. (2009). The mechanism behind microstructure formation in mixed whey protein-polysaccharide cold-set gels. Food Hydrocolloids, 23 (3), 755-764. https://doi.org/10.1016/j.foodhyd.2008.03.017.

Joyner, H. S., \& Daubert, C. R. (2017). Rheological principles for food analysis. In Food analysis (pp. 511-527). Springer. https://doi.org/10.1007/978-3-319-45776-5_29.

Ju, Z. Y., \& Kilara, A. (1998). Properties of gels induced by heat, protease, calcium salt, and acidulant from calcium ion-aggregated whey protein isolate. Journal of Dairy Science, 81(5), 1236-1243. https://doi.org/10.3168/jds.S0022-0302(98)75684-X.

Kang, K.S., \& Veeder, G.T. (1983). 4377636 Polysaccharide S-60 and bacterial fermentation process for its preparation. Google Patents. https://patents.google.co $\mathrm{m} /$ patent/US4326053A/en.

Khan, S., Amin, N., Ansari, Z., \& Majumder, D. R. (2015). Whey: Waste to health and wealth. International Journal of Current Mocrobiology and Applied Sciences, 245-253.

Kim, H. W., Bae, H., \& Park, H. J. (2017). Classification of the printability of selected food for 3D printing: Development of an assessment method using hydrocolloids as reference material. Journal of Food Engineering, 215(Supplement C), 23-32. https:// doi.org/10.1016/j.jfoodeng.2017.07.017.
Kim, H. W., Lee, J. H., Park, S. M., Lee, M. H., Lee, I. W., Doh, H. S., et al. (2018). Effect of hydrocolloids on rheological properties and printability of vegetable inks for 3D food printing. Journal of Food Science, 83(12), 2923-2932. https://doi.org/10.1111/ 1750-3841.14391.

Kim, H. W., Lee, I. J., Park, S. M., Lee, J. H., Nguyen, M. H., \& Park, H. J. (2019). Effect of hydrocolloid addition on dimensional stability in post-processing of 3D printable cookie dough. Lebensmittel-Wissenschaft \& Technologie, 101, 69-75. https://doi.org/ 10.1016/j.lwt.2018.11.019.

Kirchmajer, D. M., Steinhoff, B., Warren, H., Clark, R., \& Het Panhuis, M. (2014) Enhanced gelation properties of purified gellan gum. In Carbohydrate Research, 388 (1), 125-129. https://doi.org/10.1016/j.carres.2014.02.018.

Lanaro, M., Forrestal, D. P., Scheurer, S., Slinger, D. J., Liao, S., Powell, S. K., et al. (2017). 3D printing complex chocolate objects: Platform design, optimization and evaluation. Journal of Food Engineering, 215, 13-22. https://doi.org/10.1016/j. jfoodeng.2017.06.029.

Larson, R. G. (1999). The structure and rheology of complex fluids (Vol. 150). New York: Oxford university press.

Le Tohic, C., O'Sullivan, J. J., Drapala, K. P., Chartrin, V., Chan, T., Morrison, A. P., et al. (2018). Effect of 3D printing on the structure and textural properties of processed cheese. Journal of Food Engineering, 220, 56-64. https://doi.org/10.1016/j. jfoodeng.2017.02.003.

Le, X. T., Rioux, L. E., \& Turgeon, S. L. (2017). Formation and functional properties of protein-polysaccharide electrostatic hydrogels in comparison to protein or polysaccharide hydrogels. Advances in Colloid and Interface Science, 239, 127-135. https://doi.org/10.1016/j.cis.2016.04.006.

Liu, Z., Bhandari, B., Prakash, S., Mantihal, S., \& Zhang, M. (2019a). Linking rheology and printability of a multicomponent gel system of carrageenan-xanthan-starch in extrusion based additive manufacturing. Food Hydrocolloids, 87, 413-424. https:// doi.org/10.1016/j.foodhyd.2018.08.026.

Liu, Z., Bhandari, B., Prakash, S., \& Zhang, M. (2018a). Creation of internal structure of mashed potato construct by 3D printing and its textural properties. Food Research International, 111, 534-543. https://doi.org/10.1016/j.foodres.2018.05.075.

Liu, Y., Liu, D., Wei, G., Ma, Y., Bhandari, B., \& Zhou, P. (2018b). 3D printed milk protein food simulant: Improving the printing performance of milk protein concentration by incorporating whey protein isolate. Innovative Food Science \& Emerging Technologies, 49, 116-126. https://doi.org/10.1016/j.ifset.2018.07.018.

Liu, Y., Yu, Y., Liu, C., Regenstein, J. M., Liu, X., \& Zhou, P. (2019b). Rheological and mechanical behavior of milk protein composite gel for extrusion-based 3D food printing. Lebensmittel-Wissenschaft \& Technologie, 102, 338-346. https://doi.org/ 10.1016/j.lwt.2018.12.053.

Liu, Z., Zhang, M., Bhandari, B., \& Wang, Y. (2017). 3D printing: Printing precision and application in food sector. Trends in Food Science \& Technology, 69, 83-94. https:// doi.org/10.1016/j.tifs.2017.08.018.

Liu, Z., Zhang, M., Bhandari, B., \& Yang, C. (2018c). Impact of rheological properties of mashed potatoes on 3D printing. Journal of Food Engineering, 220, 76-82. https://doi. org/10.1016/j.jfoodeng.2017.04.017.

Mantihal, S., Prakash, S., \& Bhandari, B. (2019). Textural modification of 3D printed dark chocolate by varying internal infill structure. Food Research International, 121, 648-657. https://doi.org/10.1016/j.foodres.2018.12.034.

McIntosh, G. H., Royle, P. J., Le Leu, R. K., Regester, G. O., Johnson, M. A., Grinsted, R. L., et al. (1998). Whey proteins as functional food ingredients? International Dairy Journal, 8(5-6), 425-434. https://doi.org/10.1016/S0958-6946 (98)00065-X.

Meng, Y. C., Hong, L. B., \& Jin, J. Q. (2013). A study on the gelation properties and rheological behavior of gellan gum. Applied Mechanics and Materials, 284-287, 20-24. https://doi.org/10.13039/10.4028/www.scientific.net/AMM.284-287.20.

Miyoshi, E., Takaya, T., \& Nishinari, K. (1994). Gel-sol transition in gellan gum solutions. I. Rheological studies on the effects of salts. Topics in Catalysis, 8(6), 505-527. https://doi.org/10.1016/S0268-005X(09)80062-3.

Monahan, F. J., German, J. B., \& Kinsella, J. E. (1995). Effect of pH and temperature on protein unfolding and thiol/disulfide interchange reactions during heat-induced gelation of whey proteins. Journal of Agricultural and Food Chemistry, 43(1), 46-52. https://doi.org/10.1021/jf00049a010.

Ouyang, L., Highley, C. B., Sun, W., \& Burdick, J. A. (2017). A generalizable strategy for the 3D bioprinting of hydrogels from nonviscous photo-crosslinkable inks. Advanced Materials, 29(8), Article 1604983. https://doi.org/10.1002/adma.201604983.

Ouyang, L., Yao, R., Zhao, Y., \& Sun, W. (2016). Effect of bioink properties on printability and cell viability for 3D bioplotting of embryonic stem cells. Biofabrication, $8(3)$, 35020. https://doi.org/10.1088/1758-5090/8/3/035020.

Pallottino, F., Hakola, L., Costa, C., Antonucci, F., Figorilli, S., Seisto, A., et al. (2016) Printing on food or food printing: A review. Food and Bioprocess Technology, 9(5), 725-733. https://doi.org/10.1007/s11947-016-1692-3.

Patel, S. (2015). Functional food relevance of whey protein: A review of recent findings and scopes ahead. Journal of Functional Foods, 19, 308-319. https://doi.org/ 10.1016/j.jff.2015.09.040 (Part A).

Paxton, N., Smolan, W., Böck, T., Melchels, F., Groll, J., \& Jungst, T. (2017). Proposal to assess printability of bioinks for extrusion-based bioprinting and evaluation of rheological properties governing bioprintability. Biofabrication, 9(4), 44107. https:// doi.org/10.1088/1758-5090/aa8dd8.

Picone, C. S. F., \& Cunha, R. L. (2011). Influence of $\mathrm{pH}$ on formation and properties of gellan gels. Carbohydrate Polymers, 84(1), 662-668. https://doi.org/10.1016/j. carbpol.2010.12.045.

Postiglione, G., Natale, G., Griffini, G., Levi, M., \& Turri, S. (2015). Conductive 3D microstructures by direct 3D printing of polymer/carbon nanotube nanocomposites via liquid deposition modeling. Composites Part A: Applied Science and Manufacturing, 76, 110-114. https://doi.org/10.1016/j.compositesa.2015.05.014. 
Prajapati, V. D., Jani, G. K., Zala, B. S., \& Khutliwala, T. A. (2013). An insight into the emerging exopolysaccharide gellan gum as a novel polymer. Carbohydrate Polymers, 93(2), 670-678. https://doi.org/10.1016/j.carbpol.2013.01.030.

Puyol, P., Pérez, M. D., \& Horne, D. S. (2001). Heat-induced gelation of whey protein isolates (WPI): Effect of $\mathrm{NaCl}$ and protein concentration. Food Hydrocolloids, 15(3), 233-237. https://doi.org/10.1016/S0268-005X(01)00018-2.

Sarker, M., Izadifar, M., Schreyer, D., \& Chen, X. (2018). Influence of ionic crosslinkers (Ca $2+/$ Ba $2+/ \mathrm{Zn} 2+$ ) on the mechanical and biological properties of 3D Bioplotted Hydrogel Scaffolds. Journal of Biomaterials Science, Polymer Edition, 29(10), 1126-1154. https://doi.org/10.1080/09205063.2018.1433420.

Schaffner, M., Rühs, P. A., Coulter, F., Kilcher, S., \& Studart, A. R. (2017). 3D printing of bacteria into functional complex materials. Science Advances, 3(12). https://doi.org/ 10.1126/sciadv.aao6804. eaao6804.

Severini, C., Derossi, A., \& Azzollini, D. (2016). Variables affecting the printability of foods: Preliminary tests on cereal-based products. Innovative Food Science \& Emerging Technologies, 38, 281-291. https://doi.org/10.1016/j.ifset.2016.10.001.

Shimada, K., \& Cheftel, J. C. (1989). Sulfhydryl group/disulfide bond interchange reactions during heat-induced gelation of whey protein isolate. Journal of Agricultural and Food Chemistry, 37(1), 161-168. https://doi.org/10.1021/jf00085a038.

Smithers, G. W. (2008). Whey and whey proteins-From "gutter-to-gold. International Dairy Journal, 18(7), 695-704. https://doi.org/10.1016/j.idairyj.2008.03.008.

Suntornnond, R., Tan, E. Y. S., An, J., \& Chua, C. K. (2016). A mathematical model on the resolution of extrusion bioprinting for the development of new bioinks. Materials, 9 (9), 756. https://doi.org/10.3390/ma9090756.

Tang, J., Tung, M. A., \& Zeng, Y. (1997). Gellan gum wins IFT's food technology industrial achievement award. Journal of Food Science, 62(9), 688-692.

Truong, V. D., Clare, D. A., Catignani, G. L., \& Swaisgood, H. E. (2004). Cross-linking and rheological changes of whey proteins treated with microbial transglutaminase. Journal of Agricultural and Food Chemistry, 52(5), 1170-1176. https://doi.org/ $10.1021 /$ jf034397c

Turgeon, S. L., Beaulieu, M., Schmitt, C., \& Sanchez, C. (2003). Protein-polysaccharide interactions: Phase-ordering kinetics, thermodynamic and structural aspects. Current Opinion in Colloid \& Interface Science, 8(4-5), 401-414. https://doi.org/10.1016/ S1359-0294(03)00093-1.

Vancauwenberghe, V., Delele, M. A., Vanbiervliet, J., Aregawi, W., Verboven, P., Lammertyn, J., et al. (2018a). Model-based design and validation of food texture of 3D printed pectin-based food simulants. Journal of Food Engineering, 231, 72-82. https://doi.org/10.1016/j.jfoodeng.2018.03.010.
Vancauwenberghe, V., Katalagarianakis, L., Wang, Z., Meerts, M., Hertog, M., Verboven, P., et al. (2017). Pectin based food-ink formulations for 3-D printing of customizable porous food simulants. Innovative Food Science \& Emerging Technologies, 42, 138-150. https://doi.org/10.1016/j.ifset.2017.06.011.

Vancauwenberghe, V., Verboven, P., Lammertyn, J., \& Nicolaï, B. (2018b). Development of a coaxial extrusion deposition for 3D printing of customizable pectin-based food simulant. Journal of Food Engineering, 225, 42-52. https://doi.org/10.1016/j. jfoodeng.2018.01.008.

de Vargas, L., Pérez-González, J., \& Romero-Barenque, J de J. (1993). Experimental evidence of slip development in capillaries and a method to correct for end effects in the flow of xanthan solutions a). Journal of Rheology, 37(5), 867-878. https://doi. org/10.1122/1.550399.

van de Velde, F., de Hoog, E. H. A., Oosterveld, A., \& Tromp, R. H. (2015). Proteinpolysaccharide interactions to alter texture. Annual Review of Food Science and Technology, 6(1), 371-388. https://doi.org/10.1146/annurev-food-022814-015558.

Vieira, M. V., Oliveira, S. M., Amado, I. R., Fasolin, L. H., Vicente, A. A., Pastrana, L. M., et al. (2020). 3D printed functional cookies fortified with Arthrospira platensis: Evaluation of its antioxidant potential and physical-chemical characterization. Food Hydrocolloids, 105893.

van Vliet, T. (2013). Rheology and fracture mechanics of foods. Rheology and fracture mechanics of foods. CRC Press. https://doi.org/10.1201/b15681.

Wakhet, S., Singh, V. K., Sahoo, S., Sagiri, S. S., Kulanthaivel, S., Bhattacharya, M. K., et al. (2015). Characterization of gelatin-agar based phase separated hydrogel, emulgel and bigel: A comparative study. Journal of Materials Science: Materials in Medicine, 26(2), 118. https://doi.org/10.1007/s10856-015-5434-2.

Wijaya, W., Patel, A. R., Setiowati, A. D., \& Van der Meeren, P. (2017). Functional colloids from proteins and polysaccharides for food applications. Trends in Food Science \& Technology, 68, 56-69. https://doi.org/10.1016/j.tifs.2017.08.003.

Yamauchi, K., Shimizu, M., \& Kamiya, T. (1980). Emulsifying properties of whey protein. Journal of Food Science, 45(5), 1237-1242. https://doi.org/10.1111/j.13652621.1980.tb06529.x.

Yang, F., Guo, C., Zhang, M., Bhandari, B., \& Liu, Y. (2019). Improving 3D printing process of lemon juice gel based on fluid flow numerical simulation. LebensmittelWissenschaft \& Technologie, 102, 89-99. https://doi.org/10.1016/j.lwt.2018.12.031.

Yang, F., Zhang, M., Bhandari, B., \& Liu, Y. (2018). Investigation on lemon juice gel as food material for 3D printing and optimization of printing parameters. LebensmittelWissenschaft und -Technologie- Food Science and Technology, 87, 67-76. https://doi. org/10.1016/j.lwt.2017.08.054. 